\title{
Production choices with water markets and risk aversion: The role of initial allocations and forward trading
}

\author{
Philippe Bontems* Céline Nauges ${ }^{\dagger}$
}

July 12, 2018

\begin{abstract}
We develop a theoretical model that describes risk-averse farmers' decisions when facing production risk due to uncertain weather conditions and when irrigation water can be traded on a market. We focus on the role of initial water allocations granted to irrigated farms at the start of the season. The presence of water markets makes the future water price uncertain and hence the value of initial water allocations uncertain. We analyse the properties of this background risk and study how initial water allocations impact farmers' land allocation decisions between an irrigated crop and a non-irrigated crop, both characterised by random expected net returns. We then extend the model by permitting irrigation water to be traded ex-ante at a known price (forward market). Finally, we illustrate our main theoretical findings using simulations. We calibrate distributions of the random variables based on observed data from the Murray-Darling Basin in Australia where a water market has been in place for several decades.
\end{abstract}

Key-words: water markets, risk, agriculture

JEL codes: D81; Q12; Q15; Q25

${ }^{*}$ Toulouse School of Economics, INRA \& IDEI, University of Toulouse Capitole, Toulouse, France.

${ }^{\dagger}$ Toulouse School of Economics, INRA, University of Toulouse Capitole, Toulouse, France. 


\section{Introduction}

In regions where water is scarce and rainfall is erratic, irrigated farms face production risk due to the uncertainty of future water availability. To help farmers manage this uncertainty, some countries (e.g., Australia, Chile, the United States) have developed water trading schemes. Water markets have been shown to increase overall welfare by permitting the reallocation of water between low-value and high-value uses (e.g., Vaux and Howitt, 1984; Garrido, 1998) and to improve efficiency in risk sharing (e.g., Lefebvre, Gangadharan and Thoyer, 2012).

We develop a theoretical model to study the (short-term) production decisions of a representative, risk-averse, farmer who is using irrigation water as an input in production and has the possibility to trade water allocations on a competitive market. Studies modeling farmers' behaviour in the presence of water institutions such as water markets are still rare (Li, Xu and Rosegrant, 2017). We are primarily interested in understanding how the level of initial water allocations granted to the farmer affects his/her production decisions. Initial allocations, which have been shown to impact market outcomes in the presence of uncertainty and risk aversion (Baldursson and von der Fehr, 2004), are one important ingredient in the design of quota systems which has not been studied in the case of water markets, as far as we know.

Irrigated farms typically face production risk due to uncertainty of future weather and hence of the availability of water over the growing season. When water allocations can be traded on a market, the price of water depends on both demand for, and supply of, irrigation water, and is thus volatile. Price volatility not only adds to the uncertainty of future water availability but also makes the value of farmers' water rights uncertain. More precisely, the uncertain value of water allocations granted to farmers generates a background risk that is going to impact their production choices if farmers are risk-averse (Eichner and Wagener, 2012). Our model accounts for these various sources of uncertainty and describes their impact on the production decisions of a single and representative risk-averse farmer. The modelling 
of the water market equilibrium is outside the scope of this article.

The main features of our model are the following: we consider a risk-averse farmer who receives an initial allocation of water that can be physically used for the production of an irrigated crop or sold on a competitive market. The price of water, which depends on supply and demand, varies over the season. Uncertainty on the price of water makes the net return of the irrigated crop random and creates a background risk for the farmer since it makes his/her initial wealth (in terms of water allocations) uncertain. At the start of the season, the farmer decides how much land to allocate to the irrigated crop and to the non-irrigated crop, the latter being also characterised by a random return (due for example - but not restricted - to weather uncertainty). In this model, a farmer's decision about the allocation of land between two risky crops can thus be seen as a portfolio decision of a risk-averse agent owning an initial (uncertain) wealth and having the possibility of investing in two (possibly correlated) risky assets, which is a setting similar to Eichner and Wagener (2012, hereafter EW). ${ }^{1}$

We follow EW in assuming that farmers' preferences are characterised by a utility function defined over the mean and variance of their random wealth. Under some assumptions about the form of farmers' risk preferences we show, in the same vein as EW, how the level of initial allocations impacts farmers' allocation of land between the irrigated crop and the nonirrigated crop. Next, we extend EW's analysis by studying the implementation of a forward market for water allocations. The possibility of trading water forward at a certain price offers farmers a new option for managing the risk brought about by the uncertainty about the price of water and hence can modify farmers' land allocation decisions.

Finally, we run simulations to illustrate our main analytical findings. We calibrate distributions of the random variables and set the level of parameters of interest using observed data from the Murray-Darling Basin (MDB) in Australia. The MDB, which covers about $14 \%$ of Australia's land mass, is the main source of irrigated agricultural production in the

\footnotetext{
${ }^{1}$ The impact of a background risk in wealth on financial decisions such as the portfolio problem has received considerable attention in the finance and insurance literature, both in the expected utility framework and in the mean-variance context. See e.g. Tsetlin and Winkler (2005), Jiang, Ma and An (2010), Li (2011) and Eeckhoudt and Gollier (2013) for a survey.
} 
country and hosts one of the most active water markets in the world.

The main contribution of this article is to model farmers' behaviour taking into account that water markets induce some background risk (due to the uncertain value of initial water allocations). Background risk is rarely considered in the agricultural economics literature which has focused primarily on production or price risk (in most cases a single source of risk is analysed). Another original feature of our model is to assume that both the irrigated and the non-irrigated productions are subject to production risk and that their risky returns are correlated with the background risk. We argue that these assumptions are more realistic in an agricultural context than the common assumption of farmers facing a single source of risk but they also quickly increase modelling complexity. Since correlated risks are not easily tractable within the usual expected utility framework, we analyse farmers' decisions in a mean-variance framework. This setting makes it possible to derive analytical results but overlooks the potential role of the third moment (asymmetry in the risk distribution).

Section 2 describes how our article relates to and contributes to the existing literature. Section 3 describes the farmer's risk preferences and the theoretical decision model where the main choice variable is land allocation between the irrigated and non-irrigated crops. In Section 4, we focus on the role of initial allocations granted to the farmer at the beginning of the season. We first discuss the characteristics of the background risk induced by these initial water allocations and the uncertainty of future water prices. Second, we show how initial allocations impact the farmer's optimal land use decision. Section 5 extends the theoretical model to allow for forward trading at the start of the season. Section 6 provides an illustration of our main theoretical findings using simulations, and Section 7 concludes.

\section{Related literature}

The literature describing the behaviour of risk-averse firms in the presence of uncertainty dates back to the 1970s and the work of Baron (1970) and Sandmo (1971). Our article relates primarily to studies that have investigated the production decisions of risk-averse 
agents in the presence of uncertainty and regulatory instruments (market-based policies). In this literature however, the main focus has been on pollution quotas or emissions taxes and the impact of uncertainty and risk aversion on firms' polluting emissions and compliance levels (e.g., Ben David et al., 2000; Baldursson and von der Fehr, 2004, 2012). ${ }^{2}$ One exception for the agricultural sector is Babcock (1990) who studied the production decisions of farmers facing marketing quotas. Similar questions on the relationship between initial quotas and production decisions in a risky context also arise in fisheries. ${ }^{3}$

Our article also relates to the literature on the design of quota systems in general, and the dependence of market outcomes on initial allocations in the presence of uncertainty and risk aversion, in particular. This dependence was proved in Baldursson and von der Fehr (2004) in a theoretical setting. The authors showed that risk-averse firms with small initial quota holdings are expected to overinvest in abatement technology, while those with large initial quota holdings are expected to underinvest. ${ }^{4}$

Other related articles include Hahn and Stavins (2011) which listed six conditions under which the final allocation of permits (after trade has occurred) and the permit price are not independent of the initial allocation of permits, ${ }^{5}$ and Fowlie and Perloff (2013) who empirically tested the independence property using data from the Southern California's Regional Clean Air Incentives Market (RECLAIM).

As far as we know, the role of initial allocations in the context of water markets has not been addressed in the literature. In recent analyses of water markets, farmers' decisions in terms of water trading have been studied using different modelling approaches: for example,

\footnotetext{
${ }^{2}$ These articles differ in terms of the source of the uncertainty faced by the agents: pollution permit prices in Ben David et al. (2000); total number of polluting firms or firm's level of pollution in Baldursson and von der Fehr (2004); and input and/or output prices in Baldursson and von der Fehr (2012).

${ }^{3}$ For a discussion of fishing quota markets, see for example Newell, Sanchirico and Kerr (2005).

${ }^{4}$ There is an assumption of zero transaction costs in Baldursson and von der Fehr (2004). Montero (1997), in a setting with transaction costs and uncertainty, showed that initial allocations have an impact on market outcomes (equilibrium prices) and welfare even in the case of risk-neutral polluting firms which receive an initial allocation of pollution permits that can be traded.

${ }^{5}$ The six conditions are: 1 ) transaction costs (such as those due to search and information or bargaining); 2) market power; 3 ) uncertainty about the future price of permits (in the presence of risk aversion and transaction costs); 4) conditional allocations of permits (e.g., conditional on output in the previous period); 5) non-cost minimising behaviour (e.g., for public firms); and 6) differentiated regulations.
} 
a non-expected utility framework in Ranjan and Shogren (2006) and a consumption-based asset pricing model in Cristi (2007). State-contingent modelling is another recent approach that has been used to describe farmers' production decisions in the presence of uncertainty and water markets in the Australian context (see, for example, Mallawaarachchi et al., 2017). Calatrava and Garrido (2005) studied how the variability in profits (caused by the uncertainty of water allocated to the farm) is modified when a market for water is put in place, and showed that risk exposure is reduced for market users, whether they participate as sellers or buyers. In Lefebvre, Gangadharan and Thoyer (2012) data from laboratory experiments were used to study the impact of differentiated water rights (high and low priority rights, the former being served first when water is scarce) on cost effectiveness and risk management properties of water markets in the presence of transaction costs. A recent article by $\mathrm{Li}, \mathrm{Xu}$ and Rosegrant (2017) comes close in spirit to our study. These authors modelled the choice of the optimal irrigated acreage under water supply uncertainty for a representative riskaverse farmer who holds water rights. In their model only the water-intensive crop is risky. The drought-tolerant crop is assumed riskless and there is no background risk. Under these assumptions, the optimal land allocation decision can be derived within the common expected utility framework and the role of the third moment (skewness) of the risk distribution can be assessed.

Finally, our article adds to the sparse literature investigating the production decisions of non-risk neutral farmers in the presence of multiple risks. Among the few articles that studied two or more risks are Coyle (1999), Isik (2002), and Serra et al. (2006). The present article is closer in spirit to Coyle (1999) and Serra et al. (2006) who analyse farmers' production decisions in a mean-variance framework, while allowing for non-neutral risk preferences. 


\section{The farmer's decision model}

\subsection{A portfolio problem}

We consider a farmer who has the possibility of allocating his land of size $l$ that we normalise to unity, to either an irrigated crop or a non-irrigated crop. We denote the share of land devoted to the irrigated production by $x$ and the share assigned to the non-irrigated production by $(1-x)$. Irrigation water can be bought or sold on a competitive market at price $r$. From an ex-ante perspective, the water price $r$ is random with mean $\bar{r}$ because it is the outcome of supply and demand for irrigation water.

The (per hectare) net benefit of both the irrigated crop and the non-irrigated crop are random and denoted $R$ and $\varepsilon$ respectively, with means $\bar{R}$ and $\bar{\varepsilon}$. Randomness in the return of the irrigated crop is mainly driven by the uncertain water price $r$. Implicitly, the ex-post net return $R$ of the irrigated crop can be defined as: $R=\max _{z}(p f(z, \theta)-r z) x$ with $z$, the quantity of water supplied through irrigation and sold on a competitive market at price $r$; $f$, a production function that is assumed to be increasing and concave in $z ; \theta$, a random production shock, and $p$, the crop price.

Randomness in the return of the non-irrigated crop might be driven by variability in weather conditions through its impact on crop yield and/or by output price variability. Finally, we denote $e_{0} \geq 0$ as the initial level of water allocations which is made available to the farmer at the beginning of the growing season. The value of this initial endowment is unknown ex-ante due to the uncertainty of the water price.

The timing of farmers' decisions is the following: at the start of the growing season, initial water allocations $e_{0}$ granted to the farmers are announced and the farmers decide on the land area that will be planted with the irrigated crop $(x)$. At that time, the quantity of irrigation water that will be available in the summer (when the irrigated crop is in greatest need of water) and the price at which water will be sold, are not known with certainty. The decision made in the spring about the share of land to be irrigated $(x)$ can thus be seen as an ex-ante 
decision, before the uncertainty is resolved. In the summer, weather conditions have been observed and information on water availability is fully revealed, so farmers no longer face any uncertainty. They have full information when deciding on the quantity of water used to produce the irrigated crop and on the quantity of water traded on the market (ex-post decisions). In the following we focus only on the farmer's optimal (ex-ante) decision in terms of land allocation $(x)$.

The farmer's ex-post (final) wealth, which corresponds to the sum of the net returns of the irrigated and non-irrigated productions, plus his/her initial (certain) wealth $w_{0}$, and the value of the initial water allocations $e_{0}$, is written as follows:

$$
w=w_{0}+x R+(1-x) \varepsilon+r e_{0} .
$$

The decision problem of the farmer, i.e. how to allocate land between two risky assets with uncertainty about its initial wealth, is akin to a standard portfolio choice problem. The possibility of trading water on a market allows ex-post flexibility for the producer but a strictly positive initial endowment also generates a cost in terms of risk exposure through the introduction of an (additive) background risk potentially correlated with the two risky activities, $R$ and $\varepsilon$.

Since water is used as an input in the production of the irrigated crop, we expect a higher water price $r$ to induce a lower net benefit $R$ for the irrigated production. Also, because higher water prices are more likely to be observed in dry conditions, we expect a negative correlation between $r$ and $\varepsilon$, the net benefit of the non-irrigated crop. Hence we assume in the following that the water price $r$ is negatively correlated with both $R$ and $\varepsilon$, with covariances $\sigma_{r R}<0$ and $\sigma_{r \varepsilon}<0$, respectively.

\subsection{Assumptions on farmers' preferences}

Following EW, we assume that preferences over the random ex-post wealth can be represented by a two-parameter utility function $V(\mu, v)$ where $\mu$ and $v$ are the expected value and the 
variance of the ex-post wealth, respectively. The expected ex-post wealth $\mu$ is as follows:

$$
\mu\left(x, e_{0}\right)=w_{0}+x \bar{R}+(1-x) \bar{\varepsilon}+\bar{r} e_{0} .
$$

By denoting $Y$ as the final wealth in the absence of any water endowment, $Y=w_{0}+$ $x R+(1-x) \varepsilon$, we rewrite $\mu\left(x, e_{0}\right)=\bar{Y}(x)+\bar{r} e_{0}$ with $\bar{Y}(x)=w_{0}+x \bar{R}+(1-x) \bar{\varepsilon}$. We assume in the following that the average return of the irrigated crop is larger than the average return of the non-irrigated crop: $\bar{R}>\bar{\varepsilon} .{ }^{6}$

The variance $v$ of the ex-post wealth is written as:

$$
v\left(x, e_{0}\right)=x^{2} v_{R}+(1-x)^{2} v_{\varepsilon}+e_{0}^{2} v_{r}+2 x(1-x) \sigma_{\varepsilon R}+2 x e_{0} \sigma_{r R}+2(1-x) e_{0} \sigma_{r \varepsilon},
$$

where $v_{i}$ is the variance of $i$ for $i=R, \varepsilon, r$. Denoting the covariance $\sigma_{r Y}(x)=x \sigma_{r R}+(1-$ $x) \sigma_{r \varepsilon}$ (which is $<0$ given our assumptions about correlations), and denoting the variance of $Y$ as $v_{Y}(x)=x^{2} v_{R}+(1-x)^{2} v_{\varepsilon}+2 x(1-x) \sigma_{\varepsilon R}$, we obtain:

$$
v\left(x, e_{0}\right)=v_{Y}(x)+e_{0}^{2} v_{r}+2 e_{0} \sigma_{r Y}(x) .
$$

It is easy to check that the variance is a quadratic convex function of $x$ as $\frac{\partial^{2} v}{\partial x^{2}}=v_{Y}^{\prime \prime}(x)=$ $2 v_{R-\varepsilon}>0$ where $v_{R-\varepsilon}$ is the variance of $R-\varepsilon .^{7}$

Let us now turn to assumptions about farmers' risk preferences. Following Meyer (1987), we assume that $V$ is a $C^{3}$ function with

$$
V_{\mu}>0, V_{v}<0, V_{\mu \mu}<0, V_{v \mu}>0 \text {. }
$$

The fact that $V_{v}<0$ and $V_{\mu \mu}<0$ reflects that preferences are characterised by risk aversion (while risk neutrality would correspond to $\left.V_{v}=0\right) .{ }^{8}$ We denote the marginal rate of substitution between $\mu$ and $v$ by

$$
\alpha(\mu, v)=-\frac{V_{v}}{V_{\mu}}>0
$$

\footnotetext{
${ }^{6}$ This condition implies that the expected wealth $\mu$ is increasing in the land share $x$ devoted optimally to the irrigated crop.

${ }^{7}$ For the moment, we leave the sign of $\sigma_{r Y}^{\prime}(x)=\sigma_{r R}-\sigma_{r \varepsilon}$ unspecified but, in the following, wherever needed, we use the assumption that the water price $r$ is more (negatively) correlated with $R$ than with $\varepsilon$ : $\sigma_{r Y}^{\prime}(x)=\sigma_{r R}-\sigma_{r \varepsilon}<0$. We also highlight what happens if on the contrary $\sigma_{r Y}^{\prime}(x)>0$.

${ }^{8}$ The assumption $V_{v \mu}>0$ is the analogue of prudence in the expected utility framework.
} 
which is the mean-variance counterpart of the Arrow-Pratt measure of absolute risk aversion. We assume both decreasing absolute risk aversion (DARA) preferences $\left(\alpha_{\mu}<0\right)$ and variance vulnerability $\left(\alpha_{v}>0\right)$. Under DARA preferences the marginal willingness to pay for a reduction in variance decreases when expected wealth raises. Variance vulnerability means here that the marginal willingness to pay for a reduction in variance, $\alpha$, is increasing as final wealth becomes more volatile. When these two conditions are met, the agent is said to be risk vulnerable (Eichner, 2008).

Finally, to ensure second-order conditions in optimisation programs, we consider that $V(\mu, v)$ is quasi-concave or equivalently that:

$$
\alpha \alpha_{\mu}+\alpha_{v}>0
$$

as demonstrated by Eichner (2008). ${ }^{9}$

\subsection{Farmers' optimal land use decision}

The farmer chooses the land allocation $x$ such as to maximise his (mean-variance) utility of final wealth:

$$
\max _{x} U\left(x, e_{0}\right) \equiv V\left(\mu\left(x, e_{0}\right), v\left(x, e_{0}\right)\right)
$$

For an interior solution $x^{*} \in(0,1)$, the first-order condition is written:

$$
\frac{\partial U\left(x^{*}, e_{0}\right)}{\partial x}=V_{\mu} \frac{\partial \mu}{\partial x}+V_{v} \frac{\partial v}{\partial x}=0
$$

or equivalently

$$
\frac{\partial \mu}{\partial x} / \frac{\partial v}{\partial x}=\alpha(\mu, v)
$$

Condition (1) indicates that the portfolio frontier (or transformation curve) with slope $\frac{\partial \mu}{\partial x} / \frac{\partial v}{\partial x}$ must be tangent to an indifference curve with slope $\alpha$ at the optimum. In what follows, we disregard the analysis of corner solutions and we assume that the second-order condition

\footnotetext{
${ }^{9}$ As shown by Lajeri-Chaherli (2002), this condition together with DARA preferences $\left(\alpha_{\mu}<0\right)$ is equivalent to the concept of proper risk aversion, which is more demanding than risk vulnerability.
} 
$\frac{\partial^{2} U\left(x^{*}, e_{0}\right)}{\partial x^{2}} \leq 0$ is satisfied. ${ }^{10}$

Since $\frac{\partial \mu}{\partial x}=\bar{R}-\bar{\varepsilon}>0$, it follows from (1) that necessarily $\frac{\partial v}{\partial x}>0$ at the optimum. Hence, (1) can be rewritten as:

$$
\frac{\partial \mu}{\partial x}=\alpha \frac{\partial v}{\partial x} .
$$

At the optimum, the marginal benefit of $x$, which is measured by the marginal impact of $x$ on the mean wealth $\left(\frac{\partial \mu}{\partial x}>0\right)$, is equal to its marginal cost, which here corresponds to the marginal increase in variance of wealth $\left(\frac{\partial v}{\partial x}\right)$ times the marginal willingness to pay for a reduction in variance $(\alpha)$.

This result confirms that, in the presence of risk aversion, the initial allocation $e_{0}$ impacts the ex-ante choice $x^{*}$, which is in line with Hahn and Stavins (2011)'s result that the property of the outcome being independent of the initial endowment does not hold in the presence of risk aversion. ${ }^{11}$

\section{The impact of initial water allocations}

Providing an initial endowment of water $e_{0}$ to the farmer introduces a background risk that impacts his/her ex-ante decisions. We first describe the characteristics of this background risk and then we show how these allocations impact the farmer's optimal land use decision.

\subsection{Fairness and desirability of the background risk}

Contrary to EW, the background risk in our model is always fair as

$$
\frac{\partial \mu}{\partial e_{0}}=\bar{r}>0
$$

i.e., a larger initial water allocation $e_{0}$ always raises the expected ex-post wealth. ${ }^{12}$

\footnotetext{
${ }^{10}$ We actually prove in Appendix A that

$$
\frac{\partial^{2} U\left(x^{*}, e_{0}\right)}{\partial x^{2}} \leq 0 \Leftrightarrow\left(\alpha \alpha_{\mu}+\alpha_{v}\right)\left(\frac{\partial v}{\partial x}\right)^{2}+\alpha \frac{\partial^{2} v}{\partial x^{2}} \geq 0 .
$$

Given the convexity of the variance with respect to $x$, the quasi-concavity of $V(\mu, v)$ is a sufficient condition for (2) to hold.

${ }^{11} \mathrm{~A}$ risk-neutral producer $\left(V_{v}=0 \Rightarrow \alpha=0\right)$ would choose $x^{*}=1$ if $\bar{R}>\bar{\varepsilon}$ and $x^{*}=0$ if $\bar{R}<\bar{\varepsilon}$. If $\bar{R}=\bar{\varepsilon}$, the farmer is indifferent between allocating his land to the irrigated crop and the non-irrigated crop.

${ }^{12} \mathrm{EW}$ focus on unfair background risks, as does most of the literature.
} 
The background risk is actually a risk only when its upscaling never decreases the variance of final wealth:

$$
\frac{\partial v}{\partial e_{0}}=2 e_{0} v_{r}+2 \sigma_{r Y}(x) \geq 0
$$

which happens if and only if the initial endowment is large enough for a given $x$ :

$$
e_{0} \geq \tilde{e}_{0}(x) \equiv-\frac{\sigma_{r Y}(x)}{v_{r}}
$$

When condition (5) holds, we can equivalently say that the water endowment $e_{0}$ is risk increasing. If the opposite condition holds, the initial water endowment is said to be risk decreasing. ${ }^{13}$

The background risk will be said to be undesirable if its marginal impact on utility is negative. The marginal effect of the initial endowment $e_{0}$ on utility is:

$$
\begin{aligned}
\frac{\partial U\left(x, e_{0}\right)}{\partial e_{0}} & =V_{\mu} \frac{\partial \mu}{\partial e_{0}}+V_{v} \frac{\partial v}{\partial e_{0}} \\
& =V_{\mu}\left(\frac{\partial \mu}{\partial e_{0}}-\alpha \frac{\partial v}{\partial e_{0}}\right)
\end{aligned}
$$

which holds for any $x$ including $x^{*}$ due to the envelope theorem. The background risk created by the water endowment is thus undesirable if and only if

$$
\frac{\partial \mu}{\partial e_{0}} \leq \alpha \frac{\partial v}{\partial e_{0}}
$$

which, by using (4), allows the following proposition, which holds for any $x$ including $x^{*}$, to be established:

Proposition 1 The fair background risk created by the water endowment $e_{0}$ is undesirable if and only if it is sufficiently risk increasing $\left(\frac{\partial v}{\partial e_{0}} \geq \frac{\bar{r}}{\alpha}>0\right)$.

We are able to show that, at the optimum $x=x^{*}\left(e_{0}\right)$, low values of $e_{0}$ are risk reducing and large values are risk increasing, with unclear outcomes in between (see Appendix B).

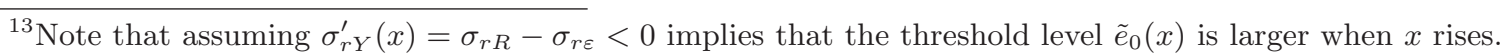
In other words, a larger land share devoted to the irrigated crop implies that the water endowment is more often risk decreasing.
} 


\subsection{Impact of the initial allocations on farmers' land use choices}

Following EW, differentiating (1) with respect to $e_{0}$ and using the second-order condition allows us to establish that:

$$
\frac{\partial x^{*}}{\partial e_{0}} \stackrel{s}{=} \underbrace{\left(-\alpha_{\mu} \frac{\partial \mu}{\partial e_{0}}\right)}_{\mathrm{ME}}+\underbrace{\left(-\alpha_{v} \frac{\partial v}{\partial e_{0}}\right)}_{\mathrm{VE}}+\underbrace{\left(-\frac{\alpha}{\left.\frac{\partial v}{\partial x} \frac{\partial^{2} v}{\partial x \partial e_{0}}\right)}\right.}_{\mathrm{CE}}
$$

As shown in (7), the marginal impact of $e_{0}$ on the optimal allocation of land can be decomposed into three terms: a mean effect (ME); a variance effect (VE); and a correlation effect $(\mathrm{CE})$. These are discussed in turn.

1. The mean effect (ME): it is always positive under DARA preferences $\left(\alpha_{\mu}<0\right)$ since the background risk is fair $\left(\frac{\partial \mu}{\partial e_{0}}=\bar{r}>0\right)$. Intuitively, increasing $e_{0}$ implies a larger positive background wealth and hence, under DARA preferences, it is optimal for the farmer to take more risk by allocating more land to the (riskier) irrigated crop.

2. The variance effect (VE): under variance vulnerability $\left(\alpha_{v}>0\right)$, the sign of the variance effect is positive when $e_{0}$ is risk decreasing and negative when $e_{0}$ is risk increasing.

3. The correlation effect $(\mathrm{CE})$ : at the optimum $x^{*}$ is risk increasing $\left(\frac{\partial v}{\partial x}>0\right)$ and we have

$$
\frac{\partial^{2} v}{\partial x \partial e_{0}}=2 \sigma_{r Y}^{\prime}\left(x^{*}\right)=2\left(\sigma_{r R}-\sigma_{r \varepsilon}\right)
$$

$\sigma_{r R}<0$ and $\sigma_{r \varepsilon}<0$. Hence, when the water price is more negatively correlated with $R$ than with $\varepsilon\left(\sigma_{r R}-\sigma_{r \varepsilon}<0\right)$, the correlation effect is positive and pushes $x^{*}$ up. ${ }^{14}$ The intuition is the following: an increase in $e_{0}$ raises the background risk which induces the risk-averse agent to diversify his portfolio by investing more in the asset that is more negatively correlated with the background risk, in our case the irrigated crop (if we assume $\left.\sigma_{r R}<\sigma_{r \varepsilon}<0\right)$.

\footnotetext{
${ }^{14}$ Conversely, if the water price were more negatively correlated with the non-irrigated crop, then the correlation effect would be negative. It would be zero if $\sigma_{r R}=\sigma_{r \varepsilon}$.
} 
When $e_{0}$ is risk decreasing at the optimum, the overall effect is positive since all three components push $x^{*}$ up. When $e_{0}$ is risk increasing, the variance effect is negative and the sign of the combined effect is ambiguous. ${ }^{15}$

These findings are summarised in the following proposition.

Proposition 2 Under the assumption that the water price is more negatively correlated with the return of the irrigated crop, an increase in the background risk (induced by a larger water endowment) induces the farmer to increase the share of irrigated land (x):

(i) when the water endowment is risk decreasing at the optimum; or

(ii) when the water endowment is risk increasing at the optimum, if and only if the correlation effect and the mean effect are strong enough to outweigh the variance effect (i.e. CE+ $M E>-V E>0)$.

\section{Introducing the possibility of forward trading}

In this section we investigate how a farmer's land allocation decision is impacted if the farmer has the possibility of buying or selling all, or a portion of, his initial water endowment on a forward market. The theoretical model described in the preceding section is extended and includes two ex-ante decisions, i.e. decisions made by the farmer at the start of the growing season before the uncertainty is resolved: (1) how much land to allocate to the irrigated crop $\left(x_{f}\right)$ and $(2)$ the quantity of water to be traded (either bought or sold) on the forward market $(y) \cdot{ }^{16}$

\footnotetext{
${ }^{15}$ Reinterpreting Proposition 4 in $\mathrm{EW}$, it is possible to show that when $e_{0}$ is undesirable and when preferences exhibit properness, then the negative variance effect always outweighs the positive mean effect. Indeed, multiplying both sides of (6) by $-\alpha_{\mu}>0$ (DARA preferences) and adding $-\alpha_{v} \frac{\partial v}{\partial e_{0}}$ to both sides of the inequality, we obtain:

$$
-\alpha_{\mu} \frac{\partial \mu}{\partial e_{0}}-\alpha_{v} \frac{\partial v}{\partial e_{0}} \leq-\left(\alpha_{\mu} \alpha+\alpha_{v}\right) \frac{\partial v}{\partial e_{0}} \leq 0 .
$$

The last component of the inequality follows from the quasi-concavity of $V\left(\alpha_{\mu} \alpha+\alpha_{v}>0\right)$ and from $\frac{\partial v}{\partial e_{0}}>0$.

${ }^{16}$ As suggested by an anonymous reviewer, the introduction of forward trading may have an effect on the spot market, on the volumes traded and on prices. Hence the mere existence of forward trading may affect the distribution of water price on the spot market. However, to take into account this potential dependence, we would have to model the market for water and derive the price equilibrium distribution, which is an interesting extension but outside the scope of this article.
} 


\subsection{Farmers' ex-post wealth}

With forward trading, the farmer can trade a quantity of water ex-ante at a known and fixed market price $r_{f}$, so his ex-post (final) wealth is:

$$
w_{f}=w_{0}+x_{f} R+\left(1-x_{f}\right) \varepsilon-r_{f}\left(y-e_{0}\right)+r y,
$$

where $y$ is the post-trade water endowment. If it is optimal for the farmer to intervene on the forward market $\left(y \neq e_{0}\right)$, then the initial endowment $e_{0}$ only generates a non-random wealth effect. The farmer can manage his exposure to the risk $r$ through his choice of both $x_{f}$ and $y$ (the farmer can choose to be a buyer if $y>e_{0}$ or a seller if $y<e_{0}$ ).

We denote $\mu_{f}$ the expectation of final wealth under forward trading, which is written:

$$
\begin{aligned}
\mu_{f}\left(x_{f}, y\right) & =w_{0}+r_{f} e_{0}+x_{f} \bar{R}+\left(1-x_{f}\right) \bar{\varepsilon}+y\left(\bar{r}-r_{f}\right) \\
& =\mu\left(x_{f}, y\right)+r_{f}\left(e_{0}-y\right) .
\end{aligned}
$$

The expected wealth $\mu_{f}$ with forward trading is equal to the expected wealth $\mu$ without forward trading where $e_{0}$ is replaced by $y$, plus an additional term $r_{f}\left(e_{0}-y\right)$ that is positive if the producer is a seller and negative if he/she is a buyer.

The variance of the final wealth $v_{f}$ is written as the variance $v$ without forward trading except that the initial endowment $e_{0}$ is being replaced by the post-trade endowment $y$ :

$$
\begin{aligned}
v_{f}\left(x_{f}, y\right) & =x_{f}^{2} v_{R}+\left(1-x_{f}\right)^{2} v_{\varepsilon}+y^{2} v_{r}+2 x_{f}\left(1-x_{f}\right) \sigma_{\varepsilon R}+2 x_{f} y \sigma_{r R}+2\left(1-x_{f}\right) y \sigma_{r \varepsilon} \\
& =v\left(x_{f}, y\right) .
\end{aligned}
$$

Note that the introduction of the forward market enlarges the decision set of the farmer. As a consequence, the farmer's utility is weakly increasing at the optimum compared to the situation without forward trading and the farmer can always reach his/her former utility level by not intervening on the forward market. 


\subsection{A farmer's optimal decisions on land use and forward trading}

With forward trading, the problem for a risk-averse farmer is to maximise his/her utility $U\left(x_{f}, y ; e_{0}\right) \equiv V\left(\mu_{f}\left(x_{f}, y\right), v_{f}\left(x_{f}, y\right)\right)$ over two decision parameters: the share of land allocated to the irrigated crop $\left(x_{f}\right)$; and the quantity of water traded ex-ante on the forward market $(y)$. Whenever it exists, an interior solution $\left(x_{f}^{*}, y^{*}\right)$ is characterised by the two following first-order conditions:

$$
\frac{\frac{\partial \mu_{f}}{\partial x_{f}}}{\frac{\partial v_{f}}{\partial x_{f}}}=\alpha\left(\mu_{f}, v_{f}\right)=\frac{\frac{\partial \mu_{f}}{\partial y}}{\frac{\partial v_{f}}{\partial y}} .
$$

Second-order conditions hold under proper risk aversion and provided correlation is not too strong as shown in Appendix C. ${ }^{17}$

As in the situation without forward trading, the optimal choice of $x_{f}$ is such that the farmer faces a trade-off between an increase in expected wealth $\left(\frac{\partial \mu_{f}}{\partial x_{f}}=\bar{R}-\bar{\varepsilon}>0\right)$ and an increase in the variance of wealth $\left(\frac{\partial v_{f}}{\partial x_{f}}>0\right)$. Similarly for the optimal choice in terms of trading on the forward market $y^{*}, \frac{\partial \mu_{f}}{\partial y}=\bar{r}-r_{f}$ and $\frac{\partial v_{f}}{\partial y}$ have the same sign but this sign depends on whether $\bar{r}-r_{f}$ is positive or negative.

When anticipations are pessimistic, i.e. biased upwards $\left(r_{f}>\bar{r}\right)$, the farmer chooses $y$ to equate his/her marginal benefit in terms of a reduction in the variance of wealth with its marginal cost in terms of expected wealth losses. Conversely, when anticipations are optimistic, i.e. biased downwards $\left(r_{f}<\bar{r}\right)$, an increase in $y$ leads to a marginal benefit in terms of expected wealth and a marginal cost in terms of increased variance. Lastly, when anticipations are not biased $\left(r_{f}=\bar{r}\right)$, the post-trade water endowment $y^{*}$ is chosen such that the variance of wealth is minimised, i.e. $\frac{\partial v_{f}}{\partial y}=0$.

In what follows, we discuss conditions under which the farmer is a net buyer or a net seller on the forward market. If we assume that $U\left(x_{f}, y\right)$ is concave in $\left(x_{f}, y\right)$, then it is possible

\footnotetext{
${ }^{17}$ Under risk neutrality $\left(V_{v}=0\right)$, only expected wealth matters and we straightforwardly obtain that when anticipations are pessimistic with respect to $\bar{r}$, i.e. biased upwards $\left(r_{f}>\bar{r}\right)$, it is optimal to sell $e_{0}$ ex-ante. On the contrary, when anticipations are optimistic, i.e. biased downwards $\left(r_{f}<\bar{r}\right)$, it is optimal to buy as much water as possible ex-ante and to re-sell it ex-post. And when anticipations are unbiased $\left(r_{f}=\bar{r}\right)$ forward trading is of no interest and $y^{*}$ is indeterminate.
} 
to derive a simple condition upon which it is optimal to sell or buy on the forward market. Consider the first-order derivative with respect to $y$ and evaluated at $y=e_{0}$ :

$$
\begin{aligned}
& \left.\left.\frac{d U}{d y}\right|_{y=e_{0}} \stackrel{s}{=} \frac{\partial \mu_{f}}{\partial y}\right|_{y=e_{0}}-\left[\alpha\left(\mu_{f}, v_{f}\right) \frac{\partial v_{f}}{\partial y}\right]_{y=e_{0}} \\
& \left.\frac{d U}{d y}\right|_{y=e_{0}} \stackrel{s}{=}\left(\bar{r}-r_{f}\right)-\alpha^{*} \frac{\partial v\left(x_{f}^{*}, e_{0}\right)}{\partial e_{0}}
\end{aligned}
$$

where $\alpha^{*} \equiv \alpha\left(\mu\left(x_{f}^{*}, e_{0}\right), v\left(x_{f}^{*}, e_{0}\right)\right)$ because $x_{f}^{*}$ is optimal if $y=e_{0}$.

Given concavity, if $\left.\frac{d U}{d y}\right|_{y=e_{0}}>0$, or equivalently $r_{f}<\bar{r}-\alpha^{*} \frac{\partial v\left(x_{f}^{*}, e_{0}\right)}{\partial e_{0}}$, then $y^{*}>e_{0}$ necessarily and the producer will be a net buyer on the forward market. Conversely, if $\left.\frac{d U}{d y}\right|_{y=e_{0}}<0$, or equivalently $r_{f}>\bar{r}-\alpha^{*} \frac{\partial v\left(x_{f}^{*}, e_{0}\right)}{\partial e_{0}}$, then $y^{*}<e_{0}$ and the producer will be a net seller. If $r_{f}=\bar{r}-\alpha^{*} \frac{\partial v\left(x_{f}^{*}, e_{0}\right)}{\partial e_{0}}$ then the producer is not active on the forward market.

Intuitively, under risk neutrality, the position on the forward market, whether buyer or seller, only depends on whether $\bar{r}-r_{f}$ is positive or negative. By contrast, under risk aversion, being a buyer or a seller also affects the variance of final wealth. Locally at $y=e_{0}$, this effect depends on whether the water endowment is risk increasing or risk decreasing. In the case of risk increasing allocations $\left(\frac{\partial v}{\partial e_{0}}>0\right)$, risk aversion gives incentives to become a seller on the forward market. It follows that it is only if anticipations are sufficiently optimistic, so that $r_{f}<\bar{r}-\alpha^{*} \frac{\partial v}{\partial e_{0}}$, that it is optimal to act as a buyer when $e_{0}$ is risk increasing. With unbiased expectations, a risk-averse producer is always a seller when $\frac{\partial v}{\partial e_{0}}>0$. Conversely, when $e_{0}$ is risk decreasing $\left(\frac{\partial v}{\partial e_{0}}<0\right)$, then risk aversion more often makes the producer a buyer. In particular, with unbiased expectations, a risk-averse farmer is always a buyer when $\frac{\partial v}{\partial e_{0}}<0$.

\subsection{The impact of initial water allocations}

We now turn to the comparative statics of the solution $\left(x_{f}^{*}, y^{*}\right)$ with respect to the initial water endowment $e_{0}$. First, note that the possibility of forward trading makes the initial allocation of water $e_{0}$ always desirable because its value is no longer random. ${ }^{18}$

\footnotetext{
${ }^{18} \mathrm{Using}$ the envelope theorem,

$$
\frac{d U}{d e_{0}}=\frac{\partial V}{\partial \mu_{f}} \frac{\partial \mu_{f}}{\partial e_{0}}=\frac{\partial V}{\partial \mu_{f}} r_{f}>0, \forall e_{0}
$$
}


Deriving the system of first-order conditions (9) and rearranging, we obtain (cf. Appendix D):

$$
\frac{d x_{f}^{*}}{d e_{0}} \stackrel{s}{=} U_{y e_{0}} U_{x y}-U_{x e_{0}} U_{y y} \stackrel{s}{=} \underbrace{\left(\bar{r}-r_{f}\right)\left(\sigma_{r \varepsilon}-\sigma_{r R}\right)}_{\text {indirect correlation effect }}+\underbrace{(\bar{R}-\bar{\varepsilon}) v_{r}}_{\text {direct mean effect }} .
$$

The marginal impact of $e_{0}$ on decision $x_{f}^{*}$ can be decomposed into a direct mean effect and an indirect correlation effect, which allows the following proposition to be derived.

Proposition 3 An increase in the initial endowment $e_{0}$ always induces the farmer to take more risk in land use if and only if anticipations are either unbiased or optimistic or not too pessimistic, i.e. $r_{f} \leq \bar{r}+\frac{(\bar{R}-\bar{\varepsilon}) v_{r}}{\left(\sigma_{r \varepsilon}-\sigma_{r R}\right)}$.

To understand this result intuitively, first consider that anticipations are unbiased. When $\bar{r}=r_{f}, y^{*}$ only aims at minimising the variance and consequently the initial water allocation whose value is non-random does not impact the marginal utility of $y\left(U_{y e_{0}}=0\right)$. Hence, only the positive direct effect $-U_{x e_{0}} U_{y y} \stackrel{s}{=}(\bar{R}-\bar{\varepsilon}) v_{r}$ remains in (10) and is explained by the fact that raising $e_{0}$ also raises the marginal utility of $x_{f}\left(U_{x e_{0}} \stackrel{s}{=} \bar{R}-\bar{\varepsilon}>0\right)$. Intuitively, a farmer with a larger $e_{0}$ gets richer and, with DARA preferences, will find it optimal to take more risk. This positive direct effect is similar to the mean effect identified in the absence of forward trading (see Proposition 2).

Regarding the indirect effect $\left(\bar{r}-r_{f}\right)\left(\sigma_{r \varepsilon}-\sigma_{r R}\right)$, the intuition is the following. Suppose that $\bar{r}>r_{f}$, then being richer (through an increase in $e_{0}$ ) stimulates the investment in $y$ that leads to a positive expected return, but at the expense of raising the background risk. Concerning the correlation effect in Proposition 2, it is optimal to diversify the portfolio by investing more in the asset that is more strongly negatively correlated with $r$, i.e. in $x_{f}$ because $\sigma_{r \varepsilon}-\sigma_{r R}>0$. Conversely, when $\bar{r}<r_{f}$, the indirect effect is negative since a positive expected return can be obtained by selling some of the initial allocation, thereby reducing the size of the background risk. It is only if anticipations are sufficiently pessimistic that the indirect effect outweighs the positive direct effect. 
Similarly, in Appendix D, we prove that:

$$
\frac{d y^{*}}{d e_{0}} \stackrel{s}{=} U_{x e_{0}} U_{x y}-U_{y e_{0}} U_{x x} \stackrel{s}{=}(\bar{R}-\bar{\varepsilon})\left(\sigma_{r \varepsilon}-\sigma_{r R}\right)+\left(\bar{r}-r_{f}\right) v_{R-\varepsilon}
$$

Hence, a similar result to Proposition 3 holds for $y^{*}$, except that the condition is now:

$$
r_{f} \leq \bar{r}+\frac{(\bar{R}-\bar{\varepsilon})\left(\sigma_{r \varepsilon}-\sigma_{r R}\right)}{v_{R-\varepsilon}}
$$

The sign of the direct mean effect $\left(\bar{r}-r_{f}\right) v_{R-\varepsilon}$ depends on whether anticipations make it worthwhile to invest or to disinvest in the water allocation. The indirect correlation effect $(\bar{R}-\bar{\varepsilon})\left(\sigma_{r \varepsilon}-\sigma_{r R}\right)$ is positive indicating that being richer due to an increase in $e_{0}$ pushes $x_{f}$ up and, by complementarity because of the correlation effect $\sigma_{r \varepsilon}-\sigma_{r R}>0$, gives incentives to increase $y$.

Finally, using the first-order conditions (9), we are also able to show that the ex-ante optimal production choice $x_{f}^{*}$ and the post-trade water endowment $y^{*}$ are linearly related (cf. Appendix E). This affine relationship contrasts with the situation without forward trading where the relationship between land use and water endowment was typically non-linear.

\subsection{Comparison of optimal land use with and without forward trading}

We discuss whether the introduction of forward trading induces the farmer to take more risk in terms of land use compared to the situation without forward trading. This could be the case because the essence of forward trading is to manage the risk brought about by the initial water endowment $e_{0}$. Formally, we would like to compare $x^{*}\left(e_{0}\right) \in \arg \max _{x} V\left(\mu\left(x, e_{0}\right), v\left(x, e_{0}\right)\right)$ with $x_{f}^{*}\left(e_{0}\right) \in \arg \max _{x_{f}} \max _{y} V\left(\mu\left(x_{f}, y\right)+r_{f}\left(e_{0}-y\right), v\left(x_{f}, y\right)\right)$. Unfortunately, there is no general result in that perspective and the comparison remains an empirical issue. Nevertheless we can express the comparison result as the outcome of two potentially conflicting forces as made clear below.

From (8), let us rewrite the final wealth as follows:

$$
w_{f}=w_{0}^{\prime}+x_{f} R+\left(1-x_{f}\right) \varepsilon+r y
$$


which is similar to the final wealth without forward trading, except that $y$ replaces $e_{0}$ (size of the background risk) and that the non-random wealth is now $w_{0}^{\prime}=w_{0}+r_{f}\left(e_{0}-y\right)$. For a given post-trade allocation $y$, there are thus the two possibilities described below.

Consider first that the producer is a net buyer $\left(y>e_{0}\right)$ on the forward market. Compared with the case without forward trading, he/she optimally chooses a lower non-random wealth $w_{0}^{\prime}<w_{0}$ in exchange for a larger size for the background risk. Under DARA preferences, we know that a lower non-random wealth would induce the producer to take less risk (wealth effect). But under the conditions of Proposition 2 and assuming that the variance effect is dominated by the mean and the correlation effects, a larger background risk would induce the producer to take more risk, i.e. to increase the share of land allocated to the irrigated crop. The impact of the buyer's strategy on the optimal choice with respect to $x_{f}$ depends on the relative magnitude of the wealth and background risk effects.

Actually a similar trade-off exists when the producer is a net seller $\left(y<e_{0}\right)$. He/she optimally chooses a higher non-random wealth $w_{0}^{\prime}>w_{0}$ in exchange for a lower size for the background risk. Once again, the impact on the optimal choice for $x_{f}$ is unclear because, on the one hand, under DARA, a higher non-random wealth induces the producer to take more risk while, on the other hand, according to Proposition 2, a lower background risk may entail the producer to take less risk. To sum up, we have the following proposition.

Proposition 4 If the farmer is a seller and if the background risk effect induces the farmer to take more risk, then the forward market pushes $x_{f}$ up. If the farmer is a buyer and if the background risk effect induces the farmer to take less risk, then the forward market diminishes $x_{f}$. Otherwise, the outcome is unclear and depends on the sign and the relative magnitude of the wealth effect and the background risk effect.

If we assume further that $U\left(x_{f}, y ; e_{0}\right)$ is concave in $\left(x_{f}, y\right)$, then we can prove that whenever the forward market allows the marginal cost of $x_{f}$ expressed as $\alpha \frac{\partial v}{\partial x_{f}}$ to be reduced, then the farmer takes more risk with forward trading. To see this, denote $\hat{y}\left(x_{f}\right)$ the opti- 
mal post-trade endowment for a given land use $x_{f}$. It is given implicitly by the first-order condition:

$$
\frac{\partial \mu_{f}\left(x_{f}, \hat{y}\left(x_{f}\right)\right)}{\partial y}=\alpha\left(\mu_{f}\left(x_{f}, \hat{y}\left(x_{f}\right)\right), v_{f}\left(x_{f}, \hat{y}\left(x_{f}\right)\right)\right) \frac{\partial v\left(x_{f}, \hat{y}\left(x_{f}\right)\right)}{\partial y}
$$

For the sake of notation, we denote $\hat{\alpha}^{*}$ the value of $\alpha\left(\mu_{f}\left(x_{f}, \hat{y}_{f}\left(x_{f}\right)\right), v\left(x_{f}, \hat{y}\left(x_{f}\right)\right)\right)$ when $x_{f}$ is set equal to $x^{*}\left(e_{0}\right)$, the optimal share of irrigated land in the absence of forward trading.

Computing the first-order condition with respect to $x_{f}$ and evaluating it at $x_{f}=x^{*}\left(e_{0}\right)$, we obtain:

$$
\left.\left.\frac{d U}{d x_{f}}\right|_{x_{f}=x^{*}\left(e_{0}\right)} \stackrel{s}{=} \frac{\partial \mu_{f}}{\partial x_{f}}\right|_{x_{f}=x^{*}\left(e_{0}\right)}-\hat{\alpha}^{*} \frac{\partial v\left(x^{*}\left(e_{0}\right), \hat{y}\left(x^{*}\left(e_{0}\right)\right)\right)}{\partial x_{f}} .
$$

As $\frac{\partial \mu_{f}}{\partial x}=\frac{\partial \mu}{\partial x}=\bar{R}-\bar{\varepsilon}$ whatever $x$ and making use of the first-order condition (3) in the absence of forward trading, we can rewrite (12) as the difference between the marginal cost of land use $x$ without and with forward trading:

$$
\left.\frac{d U}{d x_{f}}\right|_{x_{f}=x^{*}} \stackrel{s}{=} \alpha^{*} \frac{\partial v\left(x^{*}\left(e_{0}\right), e_{0}\right)}{\partial x_{f}}-\hat{\alpha}^{*} \frac{\partial v\left(x^{*}\left(e_{0}\right), \hat{y}_{f}\left(x^{*}\left(e_{0}\right)\right)\right)}{\partial x_{f}}
$$

It follows that, by concavity, if $\left.\frac{d U}{d x_{f}}\right|_{x_{f}=x^{*}\left(e_{0}\right)}>(<) 0$, then this implies that $x_{f}^{*}>(<) x^{*}$. We conclude that the ability of forward trading to push $x$ up depends on whether water trading is able to decrease the marginal cost of $x .^{19}$

\section{Illustrative simulations: the case of the MDB in Australia}

In this section we use simulated data to quantify the impact of initial water allocations on a farmer's land allocation decisions between an irrigated crop and a non-irrigated crop under conditions experienced in the MDB in Australia.

We chose to use data from the MDB because of the large number of transactions that occurred in its market for water allocations, in particular during the last decade known as the

\footnotetext{
${ }^{19}$ The ambiguity remains even in the case of unbiased expectations $\left(\bar{r}=r_{f}\right)$. In that situation, we have $\alpha^{*}>\hat{\alpha}^{*}$ because $\mu\left(x^{*}, e_{0}\right)=\mu_{f}\left(x_{f}{ }^{*}, y^{*}\right), v\left(x^{*}, e_{0}\right)<v\left(x_{f}{ }^{*}, y^{*}\right)$ as $y^{*}$ minimises the variance in that case and because $\alpha_{v}>0$. We also have that $\partial^{2} v / \partial x \partial y=2\left(\sigma_{r R}-\sigma_{r \varepsilon}\right)<0$. Hence, it is only if $\hat{y}\left(x^{*}\left(e_{0}\right)\right)>e_{0}$ that we can conclude that $x_{f}^{*}>x^{*}$.
} 
Millennium Drought (2001-2009). ${ }^{20}$ However it is important to point out that our theoretical model was not built to represent the Australian situation. We only consider farmers' shortterm decisions and their trading of water allocations, which can be seen as temporary rights. In reality, farmers can also trade water entitlements, which are permanent water rights. ${ }^{21}$ Trading of water entitlements is commonly described as a long-term decision that is often taken jointly with other (long-term) decisions such as retirement, the selling of farm assets, or the clearing of a debt. On the contrary, the trading of water allocations is commonly used as a short-term risk management tool by farmers in the MDB. In the MDB water allocations are announced at the beginning of the season and revised every two weeks based on water storage levels and expected inflows. In our model we consider only the initial level of allocations and do not allow for subsequent revisions. We also do not consider the possibility to carryover unused water to the next period (which is allowed in some sub-regions) since our decision model covers only one year.

In the following we compare land allocation decisions with and without forward trading, and under two sets of conditions (normal/average rainfall and drought conditions). ${ }^{22}$

\subsection{Choice of distributions and parameters}

We chose cotton as the irrigated crop and dry-land wheat as the non-irrigated crop under normal conditions but irrigated wheat and dry-land wheat under dry conditions because water-intensive crops such as cotton and rice are not usually grown in dry years. ${ }^{23}$ Our model includes three non-independent random variables: $r$, the water price; $R$, the net benefit per hectare for the irrigated crop; and $\varepsilon$, the net benefit per hectare for the non-

\footnotetext{
${ }^{20}$ In some years, more than $30 \%$ of announced water allocations are traded (Zuo, Nauges and Wheeler, 2015).

${ }^{21}$ Water allocations correspond to the actual volume (or allocation) of water assigned to the farmer on the basis of his water entitlements.

${ }^{22}$ At the start of the season farmers are informed about water storage in dams and the initial water allocation also provides an indication of whether dry or normal conditions are expected over the season. So it is reasonable to assume that farmers, when making their land allocation decisions, know whether a dry or a normal season is more likely to prevail.

${ }^{23}$ When a drought prevails, the price of water allocations is high and cotton farmers are usually better off not producing and selling their water allocations instead.
} 
irrigated crop. The distribution of the price of water allocations was calibrated using water trading data produced by the Australian National Water Commission (NWC). The NWC database contains records of thousands of individual water trades (volume, price and date of the transaction) in the MDB, from August 2007 until June 2010. From these data, an average water price could be calculated weekly (weights equal to the volume traded in each transaction were used to calculate the average). We calibrated the distribution of water prices using the entire series for the normal conditions scenario since it encompasses episodes of both lower-than-average and higher-than-average rainfall. For the dry conditions scenario, calibration was based on the first half of the period from August 2007 to June 2009 which was characterised by sustained lower-than-average rainfall. Data analysis and statistical tests showed that a two-parameter log-normal distribution provided a good fit of the water price series.

Beta distributions are used to describe net returns of the irrigated and non-irrigated crops. Shape parameters, lower and upper bounds of each of the four beta distributions (cotton and dry-land wheat in normal conditions and irrigated wheat and dry-land wheat in dry conditions) were determined based on reports on MDB farms' performance published by the Australian Bureau of Agricultural and Resource Economics (ABARE) for the dry conditions scenario and the New South Wales Department of Primary Industries for the normal conditions scenario. ${ }^{24}$ Table 1 provides a summary of the distributions and parameters chosen for the two scenarios.

\footnotetext{
${ }^{24}$ Beta and log-normal distributions are commonly used to describe distributions of crop yields, which are often assumed to be skewed (Babcock and Hennessy, 1996). However, there is not much discussion in the literature on the distribution of agricultural net returns. We chose the beta distribution based on official statistics for crop farms from the MDB, reporting margins for various crops. Using data from the ABARE survey of MDB irrigation farms in 2006-2007, Hughes, Mackinnon, and Ashton (2009) estimated net returns per hectare for various crops and reported quartiles of their respective distributions. Estimated returns per hectare are defined as farm cash receipts less estimated unit costs and hence can be compared to the net benefit per unit of land used in our model. These estimates were used to calibrate the beta distributions of the net returns of irrigated wheat and dry-land wheat under the dry conditions scenario, since 2006-2007 was characterised by a severe drought and historical low water allocations. For the normal conditions scenario, we used estimations of gross margins reported by the New South Wales Department of Primary Industries for (irrigated) cotton and dry-land wheat; available at http://www.dpi.nsw.gov.au/content/agriculture/farmbusiness/budgets (accessed 11 July 2018).
} 
Table 1: Parameters for the distribution of $r, R$ and $\varepsilon$

\begin{tabular}{lll}
\hline Variable & Dry conditions & Normal conditions \\
\hline$r$ & Lognormal $($ mean $=5.91 ;$ std dev $=0.42)$ & Lognormal $($ mean $=5.57 ;$ std dev $=0.61)$ \\
$R$ & Beta $(2 ; 3.3)$ with bounds $(-1,000 ; 1,200)$ & Beta $(1 ; 1.3)$ with bounds $(0 ; 4,500)$ \\
$\varepsilon$ & Beta $(2 ; 3.3)$ with bounds $(-500 ; 240)$ & Beta $(2 ; 3.3)$ with bounds $(70 ; 1,200)$ \\
\hline$r:$ price of water allocations (AUD/ML), where 1ML equals 1 million litres. \\
$R:$ net return of the irrigated crop (AUD/ha). \\
$\varepsilon:$ net return of the non-irrigated crop (AUD/ha).
\end{tabular}

The three random variables are not independent: $R$ depends on $r$ (since $r$ is the price of one essential input) and we expect these two random variables to be negatively correlated. We set the Spearman rank correlation coefficient at $\rho_{1}(r, R)=-0.3$. If uncertainty in the non-irrigated activity is mainly driven by rainfall patterns, we expect the net benefit per hectare of the non-irrigated activity $(\varepsilon)$ to be lower (due to a lower yield) when rainfall is scarce and hence when $r$ is high. We thus also expect a negative correlation between $\varepsilon$ and $r$. We set the Spearman rank correlation at $\rho_{2}(\varepsilon, r)=-0.2$. In order to generate pairs of random variables with some degree of dependence, we follow the procedure described in Johnson and Tenenbein (1981); see Appendix F for greater details. ${ }^{25}$

For both the normal and dry conditions scenarios, our simulation results are averages calculated over 50 draws of the following set of parameters: $\bar{R}, \bar{\varepsilon}, \bar{r}, \sigma_{\varepsilon}, \sigma_{R}, \sigma_{r}, \sigma_{\varepsilon R}, \sigma_{r R}$ and $\sigma_{r \varepsilon}$. Average values for these parameters under the dry and normal conditions are shown in Table $2 .^{26}$

In order to simulate our theoretical model, values also need to be chosen for the following parameters:

- Initial farmer's wealth: we set initial wealth $\left(w_{0}\right)$ at 5,000,000 AUD. This corresponds to the (farm average) total value of capital in fiscal year 2007-2008 for the irrigated broadacre farms in the MDB (Ashton, Hooper, and Oliver, 2010).

\footnotetext{
${ }^{25}$ This approach was used in Babcock and Hennessy (1996) to simulate price and crop yields.

${ }^{26}$ The results were almost unchanged when we increased the number of draws to 100 or 150 .
} 
Table 2: Average values of the main parameters, 50 draws

\begin{tabular}{lcc}
\hline Parameter & Dry conditions & Normal conditions \\
\hline $\bar{R}$ & -181 & 1,936 \\
$\bar{\epsilon}$ & -223 & 351 \\
$\bar{r}$ & 403 & 315 \\
$\sigma_{R}$ & 351 & 1,056 \\
$\sigma_{\epsilon}$ & 124 & 190 \\
$\sigma_{r}$ & 174 & 209 \\
$\sigma_{\epsilon R}$ & 2,595 & 10,530 \\
$\sigma_{r R}$ & $-18,298$ & $-60,685$ \\
$\sigma_{r \epsilon}$ & $-7,4526$ \\
\hline$R:$ net return of the irrigated crop (AUD/ha). \\
$\varepsilon:$ net return of the non-irrigated crop (AUD/ha). \\
$r:$ price of water allocations (AUD/ML), where 1ML equals 1 million litres.
\end{tabular}

- Total farm land: we set total land $(L)$ at 2,000 hectares. This corresponds to the average area operated on broadacre irrigated farms in the MDB in fiscal year 2007-2008 (Ashton and Oliver, 2011).

- Initial water allocation: we set initial allocations $\left(e_{0}\right)$ at 2 megalitres (ML where 1ML equals 1 million litres) per hectare in the dry conditions scenario and at 3 ML per hectare in the normal conditions scenario. These figures were chosen based on the average water use for pastures and cereal crops in the MDB as reported by the Australian Bureau of Statistics. $^{27}$

Under the above assumptions, the value of the initial water allocations (calculated using the average water price) represents $32 \%$ of the farmer's initial wealth under dry conditions and $38 \%$ under normal conditions, which reflects the fact that the risk borne by farmers due to the uncertain water price is important relative to the non-random part of their wealth.

Finally we need to specify the mean-variance function. We choose a functional form for $V$ and a value for the $\gamma$ parameter such that all assumptions made in the theoretical section

\footnotetext{
${ }^{27}$ See http://www.abs.gov.au/ausstats/abs@.nsf/Lookup/4618.0main+features62011-12, accessed 11 July 2017.
} 
are satisfied: $V_{\mu}>0, V_{v}<0, V_{\mu \mu}<0, V_{v \mu}>0, \alpha_{\mu}<0$, and $\alpha_{v}>0$.

$$
V(\mu, v)=-\frac{1}{\mu^{4}-500 v^{2}} .
$$

Under these assumptions, farmers are characterised by DARA preferences and variance vulnerability. All farmers are assumed to be risk-averse and the coefficient of relative risk aversion $(R R)$ is measured as follows:

$$
R R=-\frac{\partial V / \partial v}{\partial V / \partial \mu} \times w
$$

It varies with the mean and variance of wealth $(\mu$ and $v)$ and depending on the weather conditions (dry or normal). Under the assumptions made for the simulations, the coefficient of relative risk aversion varies between 2 and 3 which, in the terminology of Anderson and Dillon (1992), corresponds to individuals being rather 'risk averse' (for $R R=2$ ) and 'very risk averse' (for $R R=3$ ).

This level of risk aversion is within the range of estimates reported in the literature and obtained from observational/survey data. Estimates of farmers' risk aversion vary significantly but high coefficients of absolute risk aversion (i.e., above 2) are not uncommon: e.g., $R R=3.7$ in Bontems and Thomas (2000); [1.4 to 6.8] in Chavas and Holt (1996); 1.5 in Isik and Khanna (2003); [1.1 to 2.5] in Lence (2000); [2.4 to 18.8] in Love and Buccola (1991); 0.35 in Pope, LaFrance and Just (2011); [3.8 to 5.4] in Saha, Shumway, and Talpaz (1994); and [0 to 5.5] in Sckokai and Moro (2006). There are few studies that measured risk aversion of Australian farmers. In Khuu and Weber (2013), the coefficient of relative risk aversion was measured at 2.7 for broadacre farmers from Western Australia. 


\subsection{Simulation results}

We varied the level of initial water allocations $\left(e_{0}\right)$ from 0 to $5 \mathrm{ML} /$ ha (in steps of $0.1 \mathrm{ML}$ ). For each level of $e_{0}$ we searched for the proportion of land allocated to the irrigated crop $(x)$ that maximised the mean-variance utility function. In each case we checked that the utility function satisfied the concavity condition.

In Figure 1a we show how the optimal land allocated to the irrigated crop $\left(x^{*}\right)$ varied for different levels of the initial water allocation $\left(e_{0}\right)$ with and without forward trading under normal conditions. Similarly, Figure 1b shows how the optimal land allocation to the irrigated crop varied under dry conditions. We assumed unbiased expectations on the forward market. This assumption is almost surely unrealistic but assuming biased expectations would also require making further hypotheses on the magnitude and direction of the bias. This case is not considered here.

Under normal conditions and without forward trading (dotted line in Figure 1a), the optimal share of irrigated land increased with the level of initial water allocations up to a level $e_{0}=3.3 \mathrm{ML} /$ ha and followed a very moderate decreasing trend for higher levels of water allocations. The share of irrigated land was close to $65 \%$ when water allocations were at their $\operatorname{maximum}\left(e_{0}=5 \mathrm{ML} / \mathrm{ha}\right)$. Initial water allocations were found to be risk-increasing in $95 \%$ of the cases (see condition (4)) so the impact of the initial endowment on the share of irrigated land depended on the relative magnitude of the correlation effect $(\mathrm{CE})$, mean effect $(\mathrm{ME})$ and variance effect (VE) as described in Proposition 2. As shown in Figure 2a, the variance effect (VE) outweighed the correlation effect (CE) and the mean effect (ME) for values above $e_{0}=3.3$, which explains the (moderate) decreasing trend in the share of irrigated land for initial water allocations greater than $3.3 \mathrm{ML} / \mathrm{ha}$.

Under dry conditions and without forward trading (dotted line in Figure 1b), the share of irrigated land increased for water allocations up to $e_{0}=0.7 \mathrm{ML} / \mathrm{ha}$, decreased for values of $e_{0}$ above $0.8 \mathrm{ML} / \mathrm{ha}$ and below $1.6 \mathrm{ML} / \mathrm{ha}$, and followed an upward trend for values above 
$e_{0}=1.6 \mathrm{ML} /$ ha. Similarly to the normal conditions scenario, the initial endowment was risk-increasing in almost all cases (94\%) so the (positive or negative) impact of the initial water allocations on the share of irrigated land was driven by the relative magnitude of the correlation, mean, and variance effects. As shown in Figure 2b, the variance effect outweighed the mean and correlation effects for values of $e_{0}=$ above $0.8 \mathrm{ML} /$ ha and below $1.6 \mathrm{ML} / \mathrm{ha}$. Above 1.6 ML/ha, the correlation effect followed a sharply increasing trend: the increase in the initial water endowment increased the background risk and induced the farmer to allocate more land to the irrigated crop because it was more strongly negatively correlated with the background risk than the rain-fed crop.

The possibility of forward trading induced the farmer (whose anticipations are unbiased) to allocate more land to the irrigated crop when the level of initial water allocations increased under both normal and dry conditions, which confirms Proposition 4. In most cases, the possibility of forward trading increased the share of irrigated land compared to the situation with no forward market. When the level of water allocations was set at $5 \mathrm{ML} /$ ha, the optimal share of irrigated land with forward trading was about $20-25 \%$ above the optimal share of irrigated land without any forward trading.

Finally, we calculated the risk premium (RP); that is, the amount of money that the farmer was willing to pay to avoid any risk (in our case, to make the variance of the final wealth equal to zero). The risk premium (RP) is such that:

$$
V(\mu, v)=V(\mu-R P, 0)
$$

In Figures $3 \mathrm{a}$ and $3 \mathrm{~b}$ we show the average risk premium (expressed as a percentage of mean wealth) calculated at the optimum for each level of initial water allocations under normal and dry conditions, respectively. ${ }^{28}$ Under both normal and dry conditions, the risk premium increased with the initial water endowment when forward trading was not permitted (dotted lines). It was relatively moderate for small levels of initial water allocations ( $e_{0}$ lower than

\footnotetext{
${ }^{28}$ Initial wealth is included in the computation of mean wealth.
} 
1.5 ML/ha): around 6-7\% of mean wealth under normal conditions without forward trading and almost zero under dry conditions. The risk premium increased significantly for values of initial water allocations above $1.5 \mathrm{ML} /$ ha to reach $30 \%$ (of mean wealth) under normal conditions and $44 \%$ under dry conditions, when the level of initial water allocations was at its maximum (5 ML/ha). ${ }^{29}$ The introduction of forward markets (plain lines in Figures 3a and $3 \mathrm{~b}$ ) made the risk premium almost constant over all levels of initial water allocations.

\section{Conclusion}

This article provides some new insights into risk-averse farmers' behaviour when farmers face production risk due to the uncertainty of future weather and when irrigation water can be traded on a market. Water markets have been shown to improve the efficiency of resource and risk sharing when water is scarce but in this article we focus instead on the role of initial water allocations as a background risk (induced by the uncertainty about the market price of water). We consider a risk-averse farmer who grows an irrigated crop and a non-irrigated crop and receives an initial water endowment at the start of the season. In this context, the expected net returns of the two crops are unknown ex-ante because of the uncertain amount of irrigation water and rainfall that will be available over the season; these random net returns are also likely to be correlated with the background risk. We show that risk-averse farmers' decisions about land allocation between the irrigated and non-irrigated activities depend on whether the background risk is decreasing or increasing at the optimum, and on the relative magnitude of three effects (labelled mean, variance, and correlation effects). These findings are similar to those established by EW for a risk-averse agent owning a portfolio with two risky assets in the presence of a background risk. However the background risk is fair in our setting, which differs from EW's framework. We then extend the model to allow farmers to trade water ex-ante (at the start of the season) at a known price. Our theoretical findings

\footnotetext{
${ }^{29}$ The high level of the relative risk premium is partly driven by the high level of risk aversion implied by the chosen utility function. Note however that relative risk premia of about $20 \%$ have been estimated in Groom et al. (2008) for irrigated farmers (in Cyprus) facing a severe risk of water shortage. Also in Koundouri et al. (2009) on Finnish farms, the relative risk premium was as high as $45 \%$ of profit in some years.
} 
show that the impact of the initial water endowment on land allocation decisions is unclear in most cases and depends on whether farmers' anticipations are unbiased, pessimistic or optimistic. To illustrate our main theoretical findings and get a sense of the magnitude of the effects, we ran simulations that are representative of conditions experienced by irrigated farms located in the MDB in Australia. We distinguished two sets of conditions: normal (or average) conditions and dry conditions. Under dry conditions, water prices were higher on average and yields of both the irrigated and the non-irrigated crops were lower than under average conditions. We specified a mean-variance utility function that has properties which are in line with the assumptions made in the theoretical section. We were able to show how the share of irrigated land varied with the level of initial water allocations under both normal and dry conditions, with and without forward trading. We were also able to quantify the risk premium farmers are willing to pay to avoid the variability of their final wealth.

Our theoretical results were derived under the assumption that farmers make decisions considering only the first two moments of the distribution of their wealth (mean and variance). ${ }^{30}$ The mean-variance framework was chosen in order to be able to derive analytical results but we are aware that this assumption might be strong since there is empirical evidence that farmers are sensitive to downside risk in some situations ${ }^{31}$ see for example Kim et al. (2014) for rice farmers in Korea, and Zuo, Nauges and Wheeler (2015) for Australian farmers. Another caveat of our analysis is that simulations with forward trading are made under the assumption that farmers have unbiased expectations about the future water price.

In terms of policy recommendations, our analysis confirms that initial water allocations impact risk-averse farmers' land use decisions. This is important for policy makers to keep in mind when designing market rules and when setting the level of initial water allocations. Along these lines, an interesting avenue for future research would be to study the regulator's choice of the initial water allocations to be granted to the farmers so that social welfare is

\footnotetext{
${ }^{30}$ See Eichner and Wagener (2011) for a three-moment decision model without background risk.

${ }^{31}$ Downside risk is the risk located in the lower tail of the payoff distribution and is related to the third moment, or skewness, of the distribution.
} 
maximised. The latter should not only account for the impact on farmers' wealth but should also include the costs and benefits for the environment of the chosen level of water allocations and subsequent farmers' decisions in terms of land allocation and quantity of irrigation water used. The main issue would be to understand under which conditions it can be useful for a regulator to restrict initial allocations in order to control the development of irrigation.

\section{Supplementary data}

Supplementary data are available at ERAE online.

\section{Acknowledgements}

We are grateful to participants at the University of Queensland (UQ) Applied Economics Seminar (Brisbane, Australia), the 'Environmental and Natural Resources Conservation: Theoretical and Empirical Issues' workshop organised in Montpellier (France), and the Conference of the Australian Agricultural and Resource Economics Society (AARES) held in Port Macquarie (Australia). We also thank Christian Gollier, John Quiggin, and three anonymous referees for insightful comments. This research was supported by Australian Research Council fellowship FT100100708.

\section{References}

[1] Anderson, J.R. and Dillon, J.L. (1992). Risk analysis in dryland farming systems. Farming Systems Management Series No. 2, Food and Agriculture Organization of the United Nations (FAO). FAO, Rome.

[2] Ashton, D., Hooper, S. and Oliver, M. (2010). Financial performance of irrigation farms in the Murray-Darling Basin, 2006-07 and 2007-08. ABARE-BRS Research Report 10.10, Canberra, November. Published by the Australian Bureau of Agricultural and Resource Economics-Bureau of Rural Sciences. 
[3] Ashton, D. and Oliver, M. (2011). An economic survey of irrigation farms in the MurrayDarling Basin: Industry overview and region profiles, 2008-09. ABARES Research Report 11.2, Canberra, April. Published by the Australian Bureau of Agricultural and Resource Economics and Sciences.

[4] Babcock, B.A. (1990). Acreage decisions under marketing quotas and yield uncertainty. American Journal of Agricultural Economics 72(4): 958-965.

[5] Babcock, B.A. and Hennessy, D.A. (1996). Input demand under yield and revenue insurance. American Journal of Agricultural Economics 78(2): 416-427.

[6] Baldursson, F.M. and von der Fehr, N.H.M. (2004). Price volatility and risk exposure: On market-based environmental policy instruments. Journal of Environmental Economics and Management 48(1): 682-704.

[7] Baldursson, F.M. and von der Fehr, N.H.M. (2012). Price volatility and risk exposure: On the interaction of quota and product markets. Environmental and Resource Economics 52: 213-233.

[8] Baron, D.P. (1970). Price uncertainty, utility, and industry equilibrium in pure competition. International Economic Review 11: 463-480.

[9] Ben-David, S., Brookshire, D., Burness, S., McKee, M. and Schmidt, C. (2000). Attitudes toward risk and compliance in emission permit markets. Land Economics 76(4): 590-600.

[10] Bontems, P. and Thomas, A. (2000). Information value and risk premium in agricultural production: The case of split nitrogen application for corn. American Journal of Agricultural Economics 82(1): 59-70.

[11] Calatrava, J. and Garrido, A. (2005). Spot water markets and risk in water supply. Agricultural Economics 33(2): 131-143, doi:10.1111/j.1574-0864.2005.00402. 
[12] Chavas,J.P. and Holt, M.T. (1996). Economic behavior uder uncertainty: A joint analysis of risk preferences and technology. The Review of Economics and Statistics 78(2): 329335.

[13] Cristi, O. (2007). The influence of heterogeneous risk preferences on water market activity: An application to the Paloma System of the Limari Water Basin, Chile, Ph.D. thesis, Agriculture and Resource and Economics Department, University of California, Davis.

[14] Coyle, B.T. (1999). Risk aversion and yield uncertainty in duality models of production: A mean-variance approach, American Journal of Agricultural Economics 81(3): 553-567.

[15] Eeckhoudt, L. and Gollier, C. (2013). The effects of changes in risk on risk taking: A survey. In Handbook of insurance (pp. 123-134). Springer New York.

[16] Eichner, T. (2008). Mean variance vulnerability. Management Science 54(3): 586-593.

[17] Eichner, T. and Wagener, A. (2012). Tempering effects of (dependent) background risks: A mean-variance analysis of portfolio selection. Journal of Mathematical Economics 48: $422-430$.

[18] Eichner, T. and Wagener, A. (2011). Increases in skewness and three-moment preferences. Mathematical Social Sciences 61(2): 109-113.

[19] Fowlie, M. and Perloff, J. (2013). Distributing pollution rights in cap-and-trade programs: Are outcomes independent of allocation? Review of Economics and Statistics 95(5): 1640-1652.

[20] Garrido, A. (1998). An economic analysis of water markets within the Spanish agricultural sector: Can they provide substantial benefits?, in Markets for Water: Potential and Performance, edited by K. W.Easter, M.Rosegrant, and A. Dinar, pp. 223-239, Kluwer Academic Publishers, New York. 
[21] Groom, B., Koundouri, P., Nauges, C. and Thomas, A. (2008). The story of the moment: Risk averse Cypriot farmers respond to drought management. Applied Economics 40: $315-326$.

[22] Hahn, R.W. and Stavins, R.N. (2011). The effect of allowance allocations on cap-andtrade system performance. Journal of Law and Economics 54(4): 267-294.

[23] Hughes, N., Mackinnon, D. and Ashton, D. (2009). Irrigation in the Murray-Darling Basin: Input costs, receipts and net returns in 2006-07. ABARE research report 09-20. December 2009.

[24] Isik, M. (2002). Resource management under production and output price uncertainty: Implications for environmental policy. American Journal of Agricultural Economics 84(3): $557-571$.

[25] Isik, M. and Khanna, M. (2003). Stochastic technology, risk preferences, and adoption of site-specific technologies. American Journal of Agricultural Economics 85(2): 305-317.

[26] Jiang, C., Ma, Y. and An, Y. (2010). An analysis of portfolio selection with background risk. Journal of Banking \& Finance, 34(12): 3055-3060.

[27] Johnson, M.E. and Tenenbein, A. (1981). A bivariate distribution family with specified marginals. Journal of the American Statistical Association 76(373): 198-201.

[28] Khuu, A. and Weber, E.J. (2013). How Australian farmers deal with risk. Agricultural Finance Review 73: 345-357.

[29] Kim, K., Chavas, J.P., Barham, B. and Foltz, J. (2014). Rice, irrigation and downside risk: A quantile analysis of risk exposure and mitigation on Korean farms. European Review of Agricultural Economics 41(5): 775-815. 
[30] Koundouri, P., M. Laukkanen, S. Myrra and Nauges, C. (2009). The effects of EU agricultural policy changes on farmersErisk attitudes. European Review of Agricultural Economics 36(1): 53-77.

[31] Lajeri-Chaherli, F. (2002). More on properness: The case of mean-variance preferences. Geneva Papers Risk Insurance Theory 27: 49-60.

[32] Lefebvre, M., Gangadharan, L. and Thoyer, S. (2012). Do security-differentiated water rights improve the performance of water markets? American Journal of Agricultural Economics 94(5): 1113-1135.

[33] Lence, S.H. (2000). Using consumption and asset return data to estimate farmers' time preferences and risk attitudes. American Journal of Agricultural Economics 82(4): 934947.

[34] Li, J. (2011). The demand for a risky asset in the presence of a background risk. Journal of Economic Theory, 146(1): 372-391.

[35] Li, M., Xu, W. and Rosegrant, M.W. (2017). Irrigation, risk aversion, and water right priority under water supply uncertainty. Water Resources Research 53: 7885-7903, doi:10.1002/2016WR019779.

[36] Love, A. and Buccola, S.T. (1991). Joint risk preference-technology estimation with a primal system. American Journal of Agricultural Economics 73: 765-774.

[37] Mallawaarachchi, T., Nauges, C., Sanders, O. and Quiggin, J. (2017). State-contingent analysis of farmers' response to weather variability: Irrigated dairy farming in the Murray Valley, Australia. The Australian Journal of Agricultural and Resource Economics 61(1): $36-55$.

[38] Meyer, J. (1987). Two-moment decision models and expected utility maximization. The American Economic Review 77(3): 421-430. 
[39] Montero, J.P. (1997). Marketable pollution permits with uncertainty and transaction costs. Resource and Energy Economics 20: 27-50.

[40] Newell, R.G., Sanchirico, J.N. and Kerr, S. (2005). Fishing quota markets. Journal of Environmental Economics and Management 49: 437-462.

[41] Pope, R.D., LaFrance, J.T. and Just, R.E. (2011). Agricultural arbitrage and risk preferences. Journal of Econometrics 162(1): 35-43.

[42] Ranjan, R. and Shogren, J.F. (2006). How probability weighting affects participation in water markets. Water Resources Research 42, W08426, doi: 10.1029/2005WR004543.

[43] Saha, A., Shumway, C.R. and Talpaz, H. (1994). Joint estimation of risk preference structure and technology using expo-power utility. American Journal of Agricultural Economics 76(2): 173-184.

[44] Sandmo, A. (1971). On the theory of the competitive firm under uncertainty. American Economic Review 61: 65-73.

[45] Sckokai, P. and Moro, D. (2006). Modeling the reforms of the Common Agricultural Policy for arable crops under uncertainty, American Journal of Agricultural Economics 88(1): $43-56$.

[46] Serra, T., Zilberman, D., Goodwin, B.K. and Featherstone, A. (2006). Effects of decoupling on the mean and variability of output. European Review of Agricultural Economics 33(3): 269-288.

[47] Tsetlin, I. and Winkler, R. L. (2005). Risky choices and correlated background risk. Management Science, 51(9): 1336-1345.

[48] Vaux, H.J. and Howitt, R.E. (1984). Managing water scarcity: An evaluation of interregional transfers. Water Resources Research 20(7): 785-792, doi:10.1029/WR020i007p00785. 
[49] Zuo, A., Nauges, C. and Wheeler, S.A. (2015). Farmers' exposure to risk and their temporary water trading. European Review of Agricultural Economics 42(1): 1-24. 


\section{Appendix}

\section{A Second-order condition}

Deriving the first-order condition

$$
\frac{\partial U\left(x^{*}, e_{0}\right)}{\partial x}=V_{\mu} \frac{\partial \mu}{\partial x}+V_{v} \frac{\partial v}{\partial x}=0
$$

we obtain:

$$
\begin{aligned}
\frac{\partial^{2} U\left(x^{*}, e_{0}\right)}{\partial x^{2}} & =V_{\mu \mu}\left(\frac{\partial \mu}{\partial x}\right)^{2}+2 V_{\mu v} \frac{\partial \mu}{\partial x} \frac{\partial v}{\partial x}+V_{v} \frac{\partial^{2} v}{\partial x^{2}}+V_{v v}\left(\frac{\partial v}{\partial x}\right)^{2} \\
& =\frac{\partial \mu}{\partial x}\left(V_{\mu \mu} \frac{\partial \mu}{\partial x}+V_{\mu v} \frac{\partial v}{\partial x}\right)+\frac{\partial v}{\partial x}\left(V_{\mu v} \frac{\partial \mu}{\partial x}+V_{v v} \frac{\partial v}{\partial x}\right)+V_{v} \frac{\partial^{2} v}{\partial x^{2}}
\end{aligned}
$$

From $\alpha=-V_{v} / V_{\mu}$, we deduce that:

$$
\begin{aligned}
& \alpha_{\mu}=-\left(\alpha V_{\mu \mu}+V_{\mu v}\right) / V_{\mu} \\
& \alpha_{v}=-\left(\alpha V_{\mu v}+V_{v v}\right) / V_{\mu} .
\end{aligned}
$$

Replacing in (14) and using (13), we get

$$
\begin{aligned}
\frac{\partial^{2} U\left(x^{*}, e_{0}\right)}{\partial x^{2}} & =-V_{\mu}\left(\alpha \alpha_{\mu}+\alpha_{v}\right)\left(\frac{\partial v}{\partial x}\right)^{2}+V_{v} \frac{\partial^{2} v}{\partial x^{2}} \\
& =-V_{\mu}\left[\left(\alpha \alpha_{\mu}+\alpha_{v}\right)\left(\frac{\partial v}{\partial x}\right)^{2}+\alpha \frac{\partial^{2} v}{\partial x^{2}}\right] .
\end{aligned}
$$

Hence, $\frac{\partial^{2} U\left(x^{*}, e_{0}\right)}{\partial x^{2}} \leq 0$ is equivalent to $\left(\alpha \alpha_{\mu}+\alpha_{v}\right)\left(\frac{\partial v}{\partial x}\right)^{2}+\alpha \frac{\partial^{2} v}{\partial x^{2}} \geq 0$.

\section{B Risk-increasing vs. risk-decreasing initial allocations}

We study the case of $e_{0}$ being risk increasing (or risk decreasing) at the optimum. When $x=x^{*}\left(e_{0}\right)$, condition (5) can be rewritten as:

$$
\frac{\partial v}{\partial e_{0}}=2 e_{0} v_{r}+2 \sigma_{r Y}\left(x^{*}\left(e_{0}\right)\right) \geq 0 \Leftrightarrow e_{0} \geq-\frac{\sigma_{r Y}\left(x^{*}\left(e_{0}\right)\right)}{v_{r}}(>0) .
$$

The sign of $\frac{\partial v}{\partial e_{0}}$ is the outcome of two conflicting forces. On the one hand, because $r$ is random $\left(v_{r}>0\right)$, its volatility increases the variance of wealth with a magnitude that depends 
on $e_{0}$. On the other hand, because there is a negative correlation between the background risk and the remaining wealth $Y$, an increase in the size of the background risk also reduces the variance of wealth.

Also, observe that:

$$
\left.\frac{\partial v}{\partial e_{0}}\right|_{e_{0}=0}=2 \sigma_{r Y}\left(x^{*}(0)\right)<0
$$

and

$$
\lim _{e_{0} \rightarrow \infty} \frac{\partial v}{\partial e_{0}}=+\infty
$$

because $\sigma_{r Y}\left(x^{*}\left(e_{0}\right)\right)=\sigma_{r R} x^{*}\left(e_{0}\right)+\sigma_{r \varepsilon}\left(1-x^{*}\left(e_{0}\right)\right)$ is bounded from above and below. It follows that in the neighbourhood of $e_{0}=0$ the initial allocation is risk decreasing. On the contrary, when $e_{0}$ is sufficiently large, the initial allocation is risk increasing. More precisely, the following result is established:

Proposition 5 Denote $\underline{e}_{0}$ the lowest (positive) root of the continuous function $h\left(e_{0}\right) \equiv e_{0}+$ $\frac{\sigma_{r Y}\left(x^{*}\left(e_{0}\right)\right)}{v_{r}}$. Then, $\underline{e_{0}} \in\left(-\frac{\sigma_{r \varepsilon}}{v_{r}},-\frac{\sigma_{r R}}{v_{r}}\right)$ and

(i) when $e_{0} \in\left(0, \underline{e_{0}}\right), e_{0}$ is risk decreasing, and

(ii) when $e_{0}>\frac{-\sigma_{r R}}{v_{r}}, e_{0}$ is risk increasing.

Proof: Introducing $\sigma_{r Y}\left(x^{*}\left(e_{0}\right)\right)=\sigma_{r R} x^{*}\left(e_{0}\right)+\sigma_{r \varepsilon}\left(1-x^{*}\left(e_{0}\right)\right)$ in (15), we get:

$$
\frac{\partial v}{\partial e_{0}} \geq 0 \Leftrightarrow x^{*} \leq \frac{v_{r} e_{0}+\sigma_{r \varepsilon}}{\sigma_{r \varepsilon}-\sigma_{r R}}
$$

Then if $e_{0}>-\frac{\sigma_{r R}}{v_{r}}>0$, we have $\frac{v_{r} e_{0}+\sigma_{r \varepsilon}}{\sigma_{r \varepsilon}-\sigma_{r R}}>1$ and it follows that on this range $\frac{\partial v}{\partial e_{0}}>0$ (part (ii)). Similarly, if $e_{0} \in\left(0,-\frac{\sigma_{r \varepsilon}}{v_{r}}\right)$, then $\frac{v_{r} e_{0}+\sigma_{r \varepsilon}}{\sigma_{r \varepsilon}-\sigma_{r R}}<0$ and consequently by continuity $\frac{\partial v}{\partial e_{0}}<0$ for $e_{0} \in\left(0, \underline{e_{0}}\right)(\operatorname{part}(\mathrm{i}))$.

This confirms that low values of $e_{0}$ are risk reducing and large values are risk increasing. In between, the outcome is unclear and depends on the number of roots for $h\left(e_{0}\right)$. In particular, if there is a unique root, namely $\underline{e}_{0}$, then the initial allocation is risk reducing up to the 
threshold $\underline{e_{0}}$, and then risk increasing above. ${ }^{32}$ Otherwise, there is an odd number of roots and $e_{0}$ is alternately risk increasing and risk decreasing on the range $\left(\underline{e_{0}}, \frac{-\sigma_{r R}}{v_{r}}\right)$.

\section{Second-order conditions under forward trading}

From the first-order conditions

$$
\begin{aligned}
& \frac{\partial U\left(x_{f}^{*}, y^{*} ; e_{0}\right)}{\partial x_{f}}=V_{\mu} \frac{\partial \mu_{f}}{\partial x_{f}}+V_{v} \frac{\partial v_{f}}{\partial x_{f}} \\
& \frac{\partial U\left(x_{f}^{*}, y^{*} ; e_{0}\right)}{\partial y}=V_{\mu} \frac{\partial \mu_{f}}{\partial y}+V_{v} \frac{\partial v_{f}}{\partial y}
\end{aligned}
$$

we get by derivation:

$$
\begin{aligned}
\frac{\partial^{2} U\left(x_{f}^{*}, y^{*} ; e_{0}\right)}{\partial x_{f}^{2}} & =V_{\mu \mu}\left(\frac{\partial \mu_{f}}{\partial x_{f}}\right)^{2}+V_{v v}\left(\frac{\partial v_{f}}{\partial x_{f}}\right)^{2}+2 V_{\mu v} \frac{\partial \mu_{f}}{\partial x_{f}} \frac{\partial v_{f}}{\partial x_{f}}+V_{v} \frac{\partial^{2} v_{f}}{\partial x_{f}^{2}} \\
& =-V_{\mu}\left[\left(\alpha \alpha_{\mu}+\alpha_{v}\right)\left(\frac{\partial v_{f}}{\partial x_{f}}\right)^{2}+\alpha \frac{\partial^{2} v_{f}}{\partial x_{f}^{2}}\right] \leq 0
\end{aligned}
$$

using the same reasoning as in Appendix A and under quasi-concavity of $V$ and convexity of variance w.r.t. $x_{f}$. Similarly, we get:

$$
\frac{\partial^{2} U\left(x_{f}^{*}, y^{*} ; e_{0}\right)}{\partial y^{2}}=-V_{\mu}\left[\left(\alpha \alpha_{\mu}+\alpha_{v}\right)\left(\frac{\partial v_{f}}{\partial y}\right)^{2}+\alpha \frac{\partial^{2} v_{f}}{\partial y^{2}}\right] \leq 0 .
$$

Also,

$$
\frac{\partial^{2} U\left(x_{f}^{*}, y^{*} ; e_{0}\right)}{\partial y \partial x_{f}}=V_{\mu \mu} \frac{\partial \mu_{f}}{\partial x_{f}} \frac{\partial \mu_{f}}{\partial y}+V_{\mu v} \frac{\partial \mu_{f}}{\partial x_{f}} \frac{\partial v_{f}}{\partial y}+V_{v v} \frac{\partial v_{f}}{\partial x_{f}} \frac{\partial v_{f}}{\partial y}+V_{\mu v} \frac{\partial \mu_{f}}{\partial y} \frac{\partial v_{f}}{\partial x_{f}}+V_{v} \frac{\partial^{2} v_{f}}{\partial x_{f} \partial y}
$$

and using the first-order conditions, this simplifies into

$$
\begin{aligned}
\frac{\partial^{2} U\left(x_{f}^{*}, y^{*} ; e_{0}\right)}{\partial y \partial x_{f}} & =\left(V_{\mu \mu} \alpha+V_{\mu v}\right) \alpha \frac{\partial v_{f}}{\partial x_{f}} \frac{\partial v_{f}}{\partial y}+\left(V_{\mu v} \alpha+V_{v v}\right) \frac{\partial v_{f}}{\partial x_{f}} \frac{\partial v_{f}}{\partial y}+V_{v} \frac{\partial^{2} v_{f}}{\partial x_{f} \partial y} \\
& =-V_{\mu}\left[\left(\alpha \alpha_{\mu}+\alpha_{v}\right) \frac{\partial v_{f}}{\partial x_{f}} \frac{\partial v_{f}}{\partial y}+\alpha \frac{\partial^{2} v_{f}}{\partial x_{f} \partial y}\right]
\end{aligned}
$$

recalling that $\alpha_{\mu}=-\left(\alpha V_{\mu \mu}+V_{\mu v}\right) / V_{\mu}$ and $\alpha_{v}=-\left(\alpha V_{\mu v}+V_{v v}\right) / V_{\mu}$.

\footnotetext{
${ }^{32}$ It is easy to check that there is a unique root if and only if $h\left(e_{0}\right)$ is strictly increasing, given that $h(0)<0$ and $\lim _{e_{0} \rightarrow \infty} h\left(e_{0}\right)=+\infty$. Using (15), we get $h^{\prime}\left(e_{0}\right)=1+\frac{\sigma_{r R}-\sigma_{r \varepsilon}}{v_{r}} \frac{\partial x^{*}}{\partial e_{0}}$ assuming the derivative $\frac{\partial x^{*}}{\partial e_{0}}$ exists. This indicates that there is a unique root to $h\left(e_{0}\right)$ if and only if $x^{*}$ is decreasing or does not increase too quickly with $e_{0}$, i.e. $\frac{\partial x^{*}}{\partial e_{0}}<\frac{v_{r}}{\sigma_{r \varepsilon}-\sigma_{r R}}$.
} 
Finally, we have by denoting $\Delta=\alpha \alpha_{\mu}+\alpha_{v}$,

$$
\begin{aligned}
& \frac{\partial^{2} U\left(x_{f}, y ; e_{0}\right)}{\partial x_{f}^{2}} \frac{\partial^{2} U\left(x_{f}, y ; e_{0}\right)}{\partial y^{2}}-\left(\frac{\partial^{2} U\left(x_{f}, y ; e_{0}\right)}{\partial y \partial x_{f}}\right)^{2} \\
= & V_{\mu}^{2}\left[\Delta\left(\frac{\partial v_{f}}{\partial x_{f}}\right)^{2}+\alpha \frac{\partial^{2} v_{f}}{\partial x_{f}^{2}}\right]\left[\Delta\left(\frac{\partial v_{f}}{\partial y}\right)^{2}+\alpha \frac{\partial^{2} v_{f}}{\partial y^{2}}\right]-V_{\mu}^{2}\left[\Delta \frac{\partial v_{f}}{\partial x_{f}} \frac{\partial v_{f}}{\partial y}+\alpha \frac{\partial^{2} v_{f}}{\partial x_{f} \partial y}\right]^{2} \\
= & \alpha \Delta V_{\mu}^{2}\left(\left(\frac{\partial v_{f}}{\partial x_{f}}\right)^{2} \frac{\partial^{2} v_{f}}{\partial y^{2}}+\left(\frac{\partial v_{f}}{\partial y}\right)^{2} \frac{\partial^{2} v_{f}}{\partial x_{f}^{2}}-2 \frac{\partial v_{f}}{\partial x_{f}} \frac{\partial v_{f}}{\partial y} \frac{\partial^{2} v_{f}}{\partial x_{f} \partial y}\right) \\
& +\alpha^{2} V_{\mu}^{2}\left[\frac{\partial^{2} v_{f}}{\partial x_{f}^{2}} \frac{\partial^{2} v_{f}}{\partial y^{2}}-\left(\frac{\partial^{2} v_{f}}{\partial x_{f} \partial y}\right)^{2}\right] .
\end{aligned}
$$

We now show that the variance $v_{f}$ is convex in $x_{f}$ and $y$. First, we have $\frac{\partial^{2} v_{f}}{\partial y^{2}}=2 v_{r}>0$ and $\frac{\partial^{2} v_{f}}{\partial x_{f}^{2}}=2 v_{R-\varepsilon}>0$. Moreover,

$$
\begin{aligned}
\frac{\partial^{2} v_{f}}{\partial x_{f}^{2}} \frac{\partial^{2} v_{f}}{\partial y^{2}}-\left(\frac{\partial^{2} v_{f}}{\partial x_{f} \partial y}\right)^{2} & =4 v_{R-\varepsilon} v_{r}-4\left(\sigma_{r R}-\sigma_{r \varepsilon}\right)^{2} \\
& =4 v_{R-\varepsilon} v_{r}\left(1-\rho_{r, R-\varepsilon}^{2}\right)>0
\end{aligned}
$$

where $\rho_{r, R-\varepsilon}=\operatorname{cov}(r, R-\varepsilon) / \sqrt{v_{R-\varepsilon} v_{r}}$ denotes the coefficient of correlation between $r$ and $R-\varepsilon$. It follows that (16) is positive provided that $\frac{\partial^{2} v_{f}}{\partial x_{f} \partial y}=2\left(\sigma_{r R}-\sigma_{r \varepsilon}\right)<0$ is not too strongly negative or equivalently for not too large correlations between the water price and the net returns $R$ and $\varepsilon$.

\section{Comparative statics}

Denoting the partial derivatives as $U_{i}=\partial U / \partial i$ and $U_{i j}=\partial^{2} U / \partial i \partial j$ for $i, j \in\left\{x_{f}, y, e_{0}\right\}$, the system (9) can be rewritten as follows:

$$
\begin{aligned}
& U_{x}=V_{\mu} \frac{\partial \mu_{f}}{\partial x}+V_{v} \frac{\partial v}{\partial x}=0 \\
& U_{y}=V_{\mu} \frac{\partial \mu_{f}}{\partial y}+V_{v} \frac{\partial v}{\partial y}=0
\end{aligned}
$$

The total derivative of the system is:

$$
\begin{aligned}
& \frac{d x_{f}^{*}}{d e_{0}}=\frac{1}{\Delta}\left(U_{y e_{0}} U_{x y}-U_{x e_{0}} U_{y y}\right) \\
& \frac{d y^{*}}{d e_{0}}=\frac{1}{\Delta}\left(U_{x e_{0}} U_{x y}-U_{y e_{0}} U_{x x}\right)
\end{aligned}
$$


where $\Delta=U_{x x} U_{y y}-\left(U_{x y}\right)^{2}>0$ (second-order condition).

Derivating (17) with respect to $e_{0}$, we obtain:

$$
U_{x e_{0}}=V_{\mu \mu} \frac{\partial \mu_{f}}{\partial x} \frac{\partial \mu_{f}}{\partial e_{0}}+V_{\mu v} \frac{\partial v}{\partial x} \frac{\partial \mu_{f}}{\partial e_{0}} .
$$

Using (17), we have $\frac{\partial \mu_{f}}{\partial x}=\alpha$ and replacing in (21), together with $\frac{\partial \mu_{f}}{\partial e_{0}}=r_{f}$, we get:

$$
\begin{aligned}
U_{x e_{0}} & =r_{f} \frac{\partial v}{\partial x}\left(\alpha V_{\mu \mu}+V_{\mu v}\right) \\
& =-\alpha_{\mu} V_{\mu} r_{f} \frac{\partial v}{\partial x}>0 .
\end{aligned}
$$

Using a similar reasoning, we get for $U_{y e_{0}}$ at the optimum:

$$
U_{y e_{0}}=-\alpha_{\mu} V_{\mu} r_{f} \frac{\partial v}{\partial y}
$$

the sign of which depends on the sign of $\frac{\partial v}{\partial y}$ or equivalently on the sign of $\frac{\partial \mu_{f}}{\partial y}=\bar{r}-r_{f}$.

Derivating (17) with respect to $y$, we can compute $U_{x y}$ :

$$
\begin{aligned}
U_{x y} & =\left(V_{\mu \mu} \frac{\partial \mu_{f}}{\partial y}+V_{\mu v} \frac{\partial v}{\partial y}\right) \frac{\partial \mu_{f}}{\partial x}+\left(V_{\mu v} \frac{\partial \mu_{f}}{\partial y}+V_{v v} \frac{\partial v}{\partial y}\right) \frac{\partial v}{\partial x}+V_{v} \frac{\partial^{2} v}{\partial x \partial y} \\
& =\left(\alpha V_{\mu \mu}+V_{\mu v}\right) \frac{\partial v}{\partial y} \frac{\partial \mu_{f}}{\partial x}+\left(\alpha V_{\mu v}+V_{v v}\right) \frac{\partial v}{\partial y} \frac{\partial v}{\partial x}+V_{v} \frac{\partial^{2} v}{\partial x \partial y}
\end{aligned}
$$

by using (18). By noting that $\alpha V_{\mu \mu}+V_{\mu v}=-\alpha_{\mu} V_{\mu}$ and $\alpha V_{\mu v}+V_{v v}=-\alpha_{v} V_{\mu}$ and using (18), we obtain:

$$
\begin{aligned}
U_{x y} & =-\alpha_{\mu} V_{\mu} \frac{\partial v}{\partial y} \frac{\partial \mu_{f}}{\partial x}-\alpha_{v} V_{\mu} \frac{\partial v}{\partial y} \frac{\partial v}{\partial x}+V_{v} \frac{\partial^{2} v}{\partial x \partial y} \\
& =-\left(\alpha \alpha_{\mu}+\alpha_{v}\right) V_{\mu} \frac{\partial v}{\partial y} \frac{\partial v}{\partial x}+V_{v} \frac{\partial^{2} v}{\partial x \partial y} \\
& =-V_{\mu}\left(\left(\alpha \alpha_{\mu}+\alpha_{v}\right) \frac{\partial v}{\partial y} \frac{\partial v}{\partial x}+\alpha \frac{\partial^{2} v}{\partial x \partial y}\right)
\end{aligned}
$$

the sign of which is unclear.

We can deduce from this formula the expression of $U_{x x}$ by replacing $y$ by $x$ and the expression of $U_{y y}$ by substituting $x$ with $y$ :

$$
\begin{aligned}
& U_{x x}=-V_{\mu}\left(\left(\alpha \alpha_{\mu}+\alpha_{v}\right)\left(\frac{\partial v}{\partial x}\right)^{2}+\alpha \frac{\partial^{2} v}{\partial x^{2}}\right) \\
& U_{y y}=-V_{\mu}\left(\left(\alpha \alpha_{\mu}+\alpha_{v}\right)\left(\frac{\partial v}{\partial y}\right)^{2}+\alpha \frac{\partial^{2} v}{\partial y^{2}}\right) .
\end{aligned}
$$


Both expressions are negatively valued under the assumption of quasi-concavity of $V(.,$.$) .$

Now taking all these expressions and replacing in (19), we get:

$$
\begin{aligned}
& \frac{d x_{f}^{*}}{d e_{0}} \stackrel{s}{=} U_{y e_{0}} U_{x y}-U_{x e_{0}} U_{y y} \\
& \stackrel{s}{=} \alpha_{\mu} V_{\mu} r_{f} \frac{\partial v}{\partial y} V_{\mu}\left(\left(\alpha \alpha_{\mu}+\alpha_{v}\right) \frac{\partial v}{\partial y} \frac{\partial v}{\partial x}+\alpha \frac{\partial^{2} v}{\partial x \partial y}\right)-\alpha_{\mu} V_{\mu} r_{f} \frac{\partial v}{\partial x} V_{\mu}\left(\left(\alpha \alpha_{\mu}+\alpha_{v}\right)\left(\frac{\partial v}{\partial y}\right)^{2}+\alpha \frac{\partial^{2} v}{\partial y^{2}}\right) \\
& \stackrel{s}{=} \alpha_{\mu} V_{\mu} r_{f} \frac{\partial v}{\partial y} V_{\mu}\left(\alpha \frac{\partial^{2} v}{\partial x \partial y}\right)-\alpha_{\mu} V_{\mu} r_{f} \frac{\partial v}{\partial x} V_{\mu}\left(\alpha \frac{\partial^{2} v}{\partial y^{2}}\right) \\
& \stackrel{s}{=} \alpha_{\mu} V_{\mu} r_{f} V_{\mu}\left(\frac{\partial \mu_{f}}{\partial y} \frac{\partial^{2} v}{\partial x \partial y}-\frac{\partial \mu_{f}}{\partial x} \frac{\partial^{2} v}{\partial y^{2}}\right)
\end{aligned}
$$

Recall that $\alpha_{\mu}<0$, so that

$$
\begin{aligned}
& \frac{d x_{f}^{*}}{d e_{0}} \stackrel{s}{=} \frac{\partial \mu_{f}}{\partial x} \frac{\partial^{2} v}{\partial y^{2}}-\frac{\partial \mu_{f}}{\partial y} \frac{\partial^{2} v}{\partial x \partial y} \\
& \stackrel{s}{=}(\bar{R}-\bar{\varepsilon}) v_{r}+\left(\bar{r}-r_{f}\right)\left(\sigma_{r \varepsilon}-\sigma_{r R}\right) .
\end{aligned}
$$

Using symmetry, we deduce that:

$$
\begin{aligned}
& \frac{d y^{*}}{d e_{0}} \stackrel{s}{=} \frac{\partial \mu_{f}}{\partial y} \frac{\partial^{2} v}{\partial x^{2}}-\frac{\partial \mu_{f}}{\partial x} \frac{\partial^{2} v}{\partial x \partial y} \\
& \stackrel{s}{=}\left(\bar{r}-r_{f}\right) v_{R-\varepsilon}+(\bar{R}-\bar{\varepsilon})\left(\sigma_{r \varepsilon}-\sigma_{r R}\right) .
\end{aligned}
$$

\section{E Affine relationship between the ex-ante optimal production choice and the post-trade water endowment}

Proposition 6 For interior solutions, the ex-ante optimal production choice $x_{f}^{*}$ and the posttrade water endowment $y^{*}$ are linearly related with slope $k$ :

$$
\frac{d x_{f}^{*}}{d y^{*}}=k \equiv \frac{(\bar{R}-\bar{\varepsilon}) v_{r}+\left(\bar{r}-r_{f}\right)\left(\sigma_{r \varepsilon}-\sigma_{r R}\right)}{(\bar{R}-\bar{\varepsilon})\left(\sigma_{r \varepsilon}-\sigma_{r R}\right)+\left(\bar{r}-r_{f}\right) v_{R-\varepsilon}}
$$

Proof: From (9), we have

$$
\frac{\bar{R}-\bar{\varepsilon}}{v_{Y}^{\prime}\left(x_{f}^{*}\right)+2 y^{*} \sigma_{r Y}^{\prime}\left(x_{f}^{*}\right)}=\frac{\bar{r}-r_{f}}{2 y^{*} v_{r}+2 \sigma_{r Y}\left(x_{f}^{*}\right)}
$$

Recall that $\sigma_{r Y}(x)=x \sigma_{r R}+(1-x) \sigma_{r \varepsilon}$ and $v_{Y}(x)=x^{2} v_{R}+(1-x)^{2} v_{\varepsilon}+2 x(1-x) \sigma_{\varepsilon R}$. Hence, replacing and rearranging, we obtain that

$$
x_{f}^{*}=\left[\frac{(\bar{R}-\bar{\varepsilon}) v_{r}+\left(\bar{r}-r_{f}\right)\left(\sigma_{r \varepsilon}-\sigma_{r R}\right)}{(\bar{R}-\bar{\varepsilon})\left(\sigma_{r \varepsilon}-\sigma_{r R}\right)+\left(\bar{r}-r_{f}\right) v_{R-\varepsilon}}\right] y^{*}+\frac{(\bar{R}-\bar{\varepsilon}) \sigma_{r \varepsilon}+\left(\bar{r}-r_{f}\right)\left(v_{\varepsilon}-\sigma_{\varepsilon R}\right)}{(\bar{R}-\bar{\varepsilon})\left(\sigma_{r \varepsilon}-\sigma_{r R}\right)+\left(\bar{r}-r_{f}\right) v_{R-\varepsilon}} .
$$


In the presence of forward trading, this relationship is affine. From (22), it is straightforward to establish that the slope is positive whenever $r_{f}$ is sufficiently small or large while it is negative for intermediary values. ${ }^{33}$ In particular, when anticipations are not biased $\left(r_{f}=\bar{r}\right)$, the post-trade water endowment $y^{*}$ is chosen such that the variance of wealth is minimised, i.e. $\frac{\partial v_{f}}{\partial y}=2 y^{*} v_{r}+2 \sigma_{r Y}\left(x_{f}^{*}\right)=0$. We thus get a positive affine relationship between $x_{f}^{*}$ and $y^{*}$, with slope:

$$
k=\frac{v_{r}}{\sigma_{r \varepsilon}-\sigma_{r R}}>0 .
$$

Hence, independently of the initial allocation $e_{0}$, there is some complementarity between the risky land use choice and the post-trade water allocation choice.

\section{F Simulation of dependent random variables}

The procedure described below allows us to generate pairs of dependent random variables $(r, R)$ and $(r, \varepsilon)$ with levels of dependence $\rho_{1}$ and $\rho_{2}$ respectively. We start by generating two random variables $r$ and $R$, where $r$ and $R$ follow a lognormal and a beta distribution, $\left(F_{r}(r)\right.$ and $\left.F_{R}(R)\right)$ respectively, with some degree of (positive) dependence between the two variables. Following Johnson and Tenenbein (1981), let

$$
U=U^{\prime}
$$

and

$$
V=c_{1} U^{\prime}+\left(1-c_{1}\right) V^{\prime}
$$

where $U^{\prime}$ and $V^{\prime}$ are identically independently distributed random variables with any common density function $g(t)$, and $c_{1}$ is a constant in the interval $(0,1)$. We follow Babcock and Hennessy (1996) and choose the standard normal distribution for $g(t)$. Different values for

\footnotetext{
${ }^{33}$ More precisely, we have $k \geq 0$ iff $\quad r_{f} \in\left[0, r_{1}\right] \cup\left[r_{2}, \infty\right)$ where $r_{1}=$ $\min \left(\bar{r}+\frac{(\bar{R}-\bar{\varepsilon})\left(\sigma_{r \varepsilon}-\sigma_{r R}\right)}{v_{R-\varepsilon}}, \bar{r}+\frac{(\bar{R}-\bar{\varepsilon}) v_{r}}{\left(\sigma_{r \varepsilon}-\sigma_{r R}\right)}\right)>\quad \bar{r}$ as $\sigma_{r \varepsilon}>\sigma_{r R}$ by assumption and $r_{2}=$ $\max \left(\bar{r}+\frac{(\bar{R}-\bar{\varepsilon})\left(\sigma_{r \varepsilon}-\sigma_{r R}\right)}{v_{R-\varepsilon}}, \bar{r}+\frac{(\bar{R}-\bar{\varepsilon}) v_{r}}{\left(\sigma_{r \varepsilon}-\sigma_{r R}\right)}\right)>r_{1}$. Conversely, $k<0$ iff $r_{f} \in\left(r_{1}, r_{2}\right)$.
} 
the constant $c_{1}$ yield different levels of dependence when dependence is measured by Spearman's rank correlation coefficient, $\rho_{1}$ (see Johnson and Tenenbein, 1981, for values of $c_{1}$ and corresponding correlation coefficient for different specifications of $g(t))$. Let $r^{\prime}=H_{1}(U)$ and $R^{\prime}=H_{2}(V)$ where $H_{1}(u)$ and $H_{2}(v)$ are the distribution functions of $U$ and $V$, respectively. It follows that:

$$
r=F_{r}^{-1}\left(r^{\prime}\right)=F_{r}^{-1}\left(H_{1}(U)\right)
$$

and

$$
R=F_{R}^{-1}\left(R^{\prime}\right)=F_{R}^{-1}\left(H_{2}(V)\right)
$$

are positively correlated with Spearman's rank correlation coefficient $\rho_{1}$ depending on the constant $c_{1}$ chosen. For negatively correlated variables, $R$ should be calculated as follows:

$$
R=F_{R}^{-1}\left(1-R^{\prime}\right)=F_{R}^{-1}\left(1-H_{2}(V)\right)
$$

We then propose repeating the same procedure to generate net returns for the nonirrigated activity. Considering a random variable $W$ and a constant $c_{2}$ (and corresponding Spearman's rank correlation $\rho_{2}$ ), we have

$$
W=c_{2} U^{\prime}+\left(1-c_{2}\right) W^{\prime}
$$

and

$$
\varepsilon=F_{\varepsilon}^{-1}\left(\varepsilon^{\prime}\right)=F_{\varepsilon}^{-1}\left(H_{3}(W)\right)
$$

where $W^{\prime}$ is identically independently distributed standard normal variable and $\varepsilon^{\prime}=H_{3}(W)$ is the marginal of $W$. 